Check for updates

Cite this: Phys. Chem. Chem. Phys., 2018, 20, 29764

Received 7th August 2018, Accepted 8th November 2018

DOI: $10.1039 / c 8 c p 05035 j$

rsc.li/pccp

\section{Understanding the interactions of imidazolium-based ionic liquids with cell membrane models $\dagger$}

\author{
Carlos M. N. Mendonça, ${ }^{a}$ Debora T. Balogh, ${ }^{b}$ Simone C. Barbosa, ${ }^{b}$ \\ Tânia E. Sintra, (D) ${ }^{a}$ Sónia P. M. Ventura, (D) ${ }^{a}$ Luís F. G. Martins, ${ }^{c d}$ Pedro Morgado, ${ }^{c}$ \\ Eduardo J. M. Filipe, ${ }^{c}$ João A. P. Coutinho, $\mathbb{D}^{\mathrm{a}}$ Osvaldo N. Oliveira Jr ${ }^{\mathrm{b}}$ and \\ Ana Barros-Timmons (D) *a
}

\begin{abstract}
Cell membrane models have been used to evaluate the interactions of various imidazolium-based ionic liquids (ILs) with Langmuir monolayers of two types of phospholipids and cholesterol. Data from surface pressure isotherms, Brewster angle microscopy (BAM) and polarization-modulated infrared reflection absorption spectroscopy (PM-IRRAS) pointed to significant effects on the monolayers of 1,2-dipalmitoylsn-glycero-3-phosphocholine (DPPC) and cholesterol, used to mimic the membranes of eukaryotic cells, for ILs containing more than 6 carbon atoms in the alkyl chain (i.e. $n>6$ ). For ILs with less hydrophobic tails $(n \leq 6)$ and low concentrations, the effects were almost negligible, therefore, such ILs should not be toxic to eukaryotic cells. The hydrophobicity of the anion was also proved to be relevant, with larger impact from ILs containing tetrafluoroborate $\left(\left[\mathrm{BF}_{4}\right]^{-}\right)$than chloride $\left(\mathrm{Cl}^{-}\right)$. Molecular dynamics simulations for DPPC monolayers at the surface of aqueous solutions of alkylimidazolium chloride $\left(\left[\mathrm{C}_{n} \mathrm{mim}\right] \mathrm{Cl}\right)$ confirm the penetration of the $\mathrm{IL}$ cations with longer alkyl chains into the phospholid monolayer and provide information on their location and orientation within the monolayer. For monolayers of dipalmitoylphosphatidyl glycerol (DPPG), which is negatively charged like bacteria cell membranes, the ILs induced much larger effects. Similarly to the results for DPPC and cholesterol, effects increased with the number of carbon atoms in the alkyl chain and with a more hydrophobic anion $\left[\mathrm{BF}_{4}\right]^{-}$. Overall, the approach used can provide relevant information of molecular-level interactions behind the toxicity mechanisms and support the design of (quantitative) structure-activity relationship models, which may help design more efficient and environmentally friendly ILs.
\end{abstract}

\section{Introduction}

Ionic liquids (ILs) are an unusual class of solvents due to their physicochemical characteristics resulting from the variety of interactions that these compounds may present and their nano structuring. Depending on the composition, ILs are organized in distinct arrangements that include a polar network with non-polar domains or even two continuous phases. Their solvation properties and high electric conductivity, ${ }^{1-3}$ together with their very low vapor pressure and flammability, have allowed them to be labeled as "green solvents". ${ }^{4}$ Yet, the fate of ILs has been a matter of concern due to their possible toxicity,

\footnotetext{
${ }^{a}$ CICECO-Aveiro Institute of Materials - Department of Chemistry, University of Aveiro, Campus de Santiago, 3810-193, Aveiro, Portugal.E-mail: anabarros@ua.pt

${ }^{b}$ Instituto de Física de São Carlos, USP, CP 369, 13566-590, São Carlos, SP, Brazil

${ }^{c}$ Centro de Quimica Estrutural, Instituto Superior Técnico, Universidade de Lisboa, 1049-001 Lisboa, Portugal

${ }^{d}$ Centro de Química de Évora, Escola de Ciências e Tecnologia, Universidade de Évora, Rua Romão Ramalho, 59, 7000-671 Évora, Portugal

$\dagger$ Electronic supplementary information (ESI) available. See DOI: 10.1039/c8cp05035j
}

bioaccumulation and low biodegradability. ${ }^{5,6}$ Standardised toxicity tests have been implemented to study the ecotoxicity profile of ILs on living organisms, ${ }^{7,8}$ and to evaluate their ecological risk towards terrestrial and aquatic environments, at different trophic levels. The $\mathrm{EC}_{50}$ values (median effective concentration) as well as other parameters considered in these methodologies (e.g. water solubility, partition coefficient, degradation rate and toxic units) have provided a good starting point for assessing their hazard effects. Furthermore, the European Union's REACH legislation requires complete evaluation of the (eco)toxicological and physicochemical properties, which is time consuming, limiting the evaluation of a breadth of varied ILs. However, the toxicity of ILs is a complicated issue since it depends on the nature of the biological system under study, ${ }^{9-11}$ as well as on the IL's structure. Therefore, the selection of toxicity data of ILs towards several organisms is crucial to optimize the synthesis and future application of new task-specific ILs. ${ }^{12}$

According to Egorova and Ananiko, the main factors governing ILs' toxicity are (i) the length of the alkyl chain(s) substituted in the cation/anion, (ii) the degree and type of functionalization in the 
side chain of the cation/anion, (iii) the anion nature, (iv) the cation nature, and (v) the mutual influence of the anion and cation, ${ }^{12}$ as well reviewed in the literature. ${ }^{13-15}$ In view of the complexity of the studies and the huge number of ILs available, ${ }^{16}$ both the OECD and $\mathrm{REACH}^{17}$ regulations recommend the use of (Quantitative) Structure-Activity Relationship [(Q)SAR] to correlate the chemical structure (or structure-related properties) and biological activity (or target property). This is aimed at reducing the time and cost of toxicity tests, and reduce animal experimentation. ${ }^{18}$ (Q)SAR models consist of mathematical equations that associate the chemical structure of compounds to their physical, chemical, biological and technological properties/activities. ${ }^{19,20}$ Predictive methods and molecular simulations have been developed to obtain information about the thermophysical properties of ILs ${ }^{21}$ as well as the interactions between ILs and lipids. ${ }^{1}$ Nevertheless, reliable information needs to be available to feed such models, particularly about molecular-level interactions between ILs and the cell membranes. This can be achieved using cell membrane models such as vesicles (i.e. bilayers of phospholipids), or Langmuir monolayers at the air/water interface. Jing et al. studied the cytotoxicity of ILs using lipid bilayers and found that imidazolium-based ILs cause bilayer swelling owing to strong hydrophobic interactions at concentrations above a lower critical value. ${ }^{22}$ For concentrations above the critical micelle concentration of the ILs, bilayer disruption is induced, which can further evolve into disintegration and formation of IL-lipid micelles in aqueous suspensions. These effects occur at lower concentrations with longer alkyl chain lengths of the imidazolium cation and are further accentuated when the anion also has hydrophobic characteristics. Interestingly, the lower critical concentration for bilayer swelling is similar to that of $\mathrm{EC}_{50}$ values of animal cells. Sharma et al. ${ }^{23}$ have published a review on biophysical methods used to decipher the interactions between imidazolium based ILs and DPPC as a model biomembrane. Using the Langmuir-Blodgett technique, differential scanning calorimetry, reflectivity, elastic intensity scans, quasielastic neutron scattering, and molecular dynamics simulations, the authors have shown that ILs penetrate the cell membrane perturbing the structure, dynamics and phase behavior of the membrane. Despite this relevant contribution a detailed understanding of the nature of interactions of ILs with the cell membrane requires further studies.

Taking into account the suitability of Langmuir monolayers to determine the mechanisms behind the physiological action of biologically relevant molecules, ${ }^{24,25}$ including that of ILs, ${ }^{26-28}$ in this study we assess, in a systematic manner, the interactions established using a family of alkylimidazolium chloride based ILs with substituted chain lengths varying from two to ten carbons $\left(\left[\mathrm{C}_{n} \mathrm{mim}\right] \mathrm{Cl}\right.$, with $n=2,4,6,8$ or 10$)$. Moreover, the data on the imidazolium cation were compared with the effect of the cholinium chloride $([\mathrm{Chol}] \mathrm{Cl})$ structure, as well as with alkylimidazolium tetrafluoroborate $\left[\mathrm{C}_{n} \mathrm{mim}\right]\left[\mathrm{BF}_{4}\right]$ (with $n=4,6$ or 8), to study the effect of the anion. Two phospholipids (PL) and cholesterol were used as membrane models to carry out surface pressure versus area isotherms and to investigate morphology changes with Brewster angle microscopy (BAM). Additionally, for the most representative cases, Polarization Modulated Infrared Reflection Absorption Spectroscopy (PM-IRRAS) was used to identify the functional groups involved in the PL/IL interactions, thus contributing to a more complete understanding of the mechanisms behind the toxicity induced by ILs in living organisms. As in the work reported by Wang et $a .^{28}$ who have used all-atom molecular dynamics (MD) simulations for a similar system, in order to obtain a preliminary molecular level insight into the experimental macroscopic results, molecular dynamics simulations have been performed. Given the complexity of the system, the purpose of the simulations is to gather structural arguments that support the proposed interpretations, rather than quantitative confirmation of the experimental results.

\section{Materials and methods}

\section{Materials}

1-Ethyl-3-methylimidazolium chloride $\left(\left[\mathrm{C}_{2} \mathrm{mim}\right] \mathrm{Cl}\right)$, 1-butyl-3methylimidazolium chloride $\left(\left[\mathrm{C}_{4} \mathrm{mim}\right] \mathrm{Cl}\right)$, 1-hexyl-3-methylimidazoliumchloride ([ $\left.\left.\mathrm{C}_{6} \mathrm{mim}\right] \mathrm{Cl}\right)$, 1-methyl-3-octylimidazolium chloride $\left(\left[\mathrm{C}_{8} \mathrm{mim}\right] \mathrm{Cl}\right)$ and 1-decyl-3-methylimidazolium chloride $\left(\left[\mathrm{C}_{10} \mathrm{mim}\right] \mathrm{Cl}\right)$ were purchased from Iolitec (Ionic Liquid Technologies, Germany). Cholinium chloride ([Chol] $\mathrm{Cl})$ (98 wt\%) and cholesterol were purchased from Sigma-Aldrich. 1,2-Dipalmitoyl-sn-glycero-3phosphocholine (DPPC) ( $\geq 99 \%$ ) and dipalmitoylphosphatidyl glycerol (sodium salt) (DPPG) $(\geq 99 \%)$ were purchased from Avanti Polar Lipids. Ultrapure water, $\mathrm{pH}=5.70$ and resistivity 18.2 $\mathrm{M} \Omega \mathrm{cm}$, was provided by a Millipore purification system and used to prepare all IL aqueous solutions. Chloroform, HPLC grade (99.9\%), was acquired from Sigma-Aldrich. The chemical structures of the phospholipids used are shown in Fig. 1 as well as those of the different ILs, and cholesterol.

\section{Methodology}

A Langmuir trough, KSV/NIMA model KN2002 from Biolin Scientific, located in a class 10000 clean room was used to prepare the Langmuir films at room temperature, $23 \pm 1{ }^{\circ} \mathrm{C}$. Surface pressure-area $(\pi-A)$ isotherms were recorded using a Wilhelmy plate balance. Typically, monomolecular films were produced by spreading $24 \mu \mathrm{L}$ of a chloroform solution of the

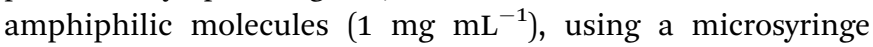
(Hamilton, $25 \mu \mathrm{L}$ ), at the air-water interface. Langmuir monolayers were allowed to reach equilibrium for $10 \mathrm{~min}$ before compression. The compression rate applied to the pressurearea isotherm measurements was $10 \mathrm{~mm} \mathrm{~min}^{-1}\left(2.4 \AA^{2} \mathrm{~min}^{-1}\right)$. The influence of the different ILs in the subphase of the neutral/zwitterionic (DPPC) Langmuir monolayers was studied at several concentrations by diluting the ILs in ultrapure water.

BAM images were recorded at the air-water interface of a Langmuir Mini trough from KSV mounted on an EP4 imaging ellipsometer from Accurion using an Ultraobjective at angles of incidence and view of $53.1^{\circ}$, with the polarizer at $10^{\circ}$, analyzer at $2^{\circ}$ and compensator at 0 . Images were geometrically corrected with the Data Studio software from Accurion. Polarization-modulated infrared reflection absorption spectra (PM-IRRAS) were recorded 


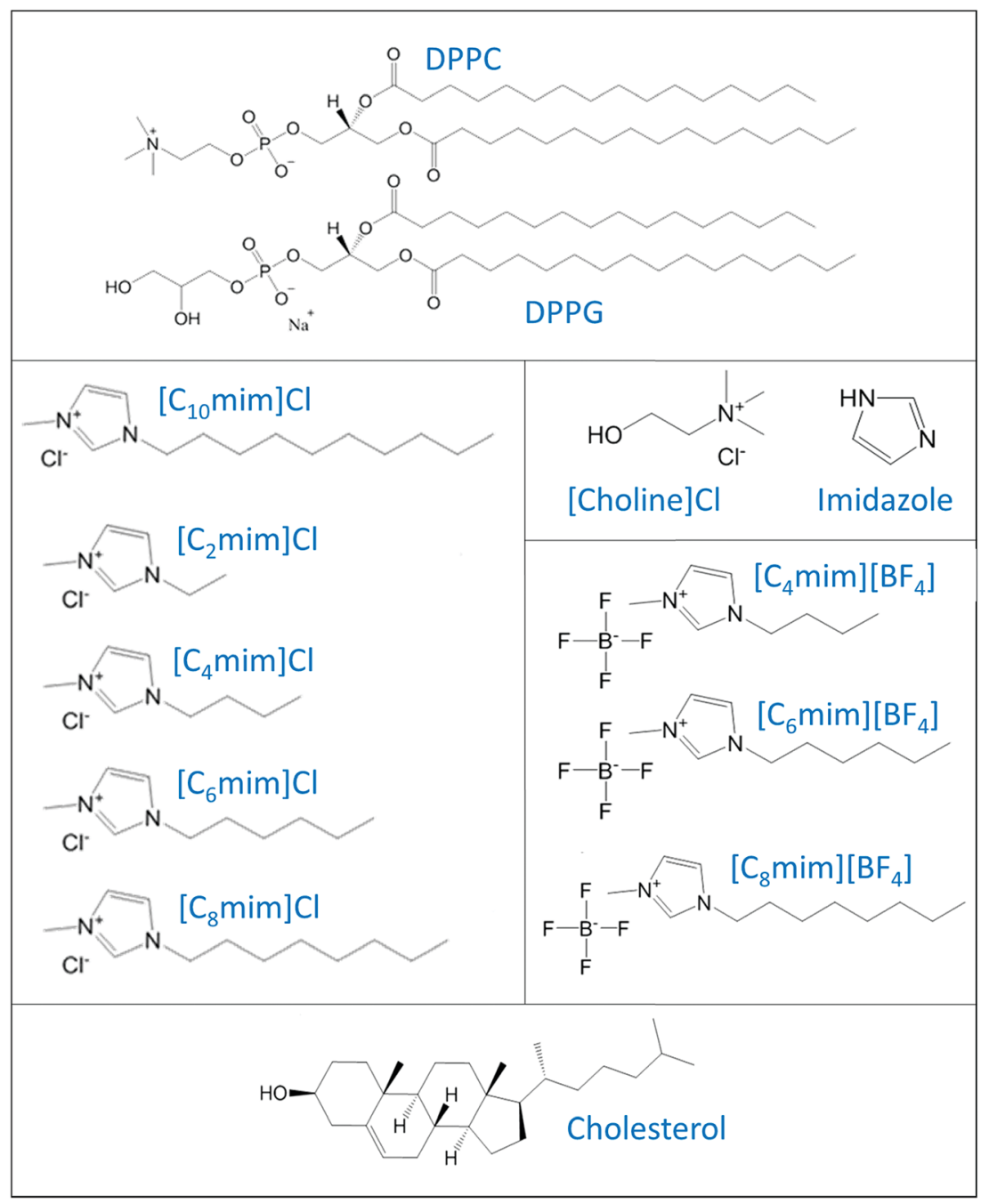

Fig. 1 Chemical structures of DPPC, DPPG, ILs studied and cholesterol.

on a KSV PMI 550 instrument (KSV Instruments Ltd, Helsinki, Finland) using an incident angle of $81^{\circ}$ on a KSV mini-trough. Simultaneous measurements of the spectra for the two polarizations were taken by continuous modulation between s- and p-polarizations. All spectra were recorded with 6000 scans with a resolution of $8 \mathrm{~cm}^{-1}$ using the spectrum of water or the respective IL aqueous solution as a background.

Molecular Dynamics (MD) simulations were performed for DPPC monolayers in water or aqueous solutions of the $\left[\mathrm{C}_{n} \mathrm{mim}\right] \mathrm{Cl}$ based IL family for alkyl chains containing $n=2,4,6,8$ and 10 carbon atoms, using GROMACS $4.5 .5 .^{29,30}$ All the substances were modelled by the general Optimized Potentials for Liquid Simulations (OPLS) framework: ${ }^{31}$ OPLS-UA for DPPC $^{32}$ from Liquidbook, ${ }^{33}$ CL\&P for ILs ${ }^{34}$ and TIP4P-2005 for water. ${ }^{35}$ Geometric mean rules were used to compute the potential parameters for the van der Waals interactions between atoms of different kinds.

Simulation boxes containing 5000 water molecules, $50 \mathrm{IL}$ ionic pairs and two DPPC monolayers at each solution edge (considered independent of each other) were equilibrated from
0.1 to $0.3 \mu \mathrm{s}$ in the $N V T$ ensemble, followed by a NVT $20 \mathrm{~ns}$ production run, whose trajectory file was used for analyses. The simulations were done independently at three different surface densities of DPPC, corresponding to areas per molecule of $87 \AA^{2}$ per molecule, $64 \AA^{2}$ per molecule and $49 \AA^{2}$ per molecule. An example of a typical simulation box is given in Fig. SI.1 of the ESI $\dagger$ to help visualization of the simulated systems. It is important to note that, for technical reasons, the concentrations of IL in the sub-phases are several orders of magnitude higher than those used in the experimental work. The results should thus be compared with caution and in a qualitative fashion, being essentially relevant as molecular interpretations.

All the simulations were done using a time-step of $1 \mathrm{fs}$ and cut-off values of 1.6 and $1.4 \mathrm{~nm}$ for van der Waals and electrostatic interactions respectively. For distances beyond the cut-off, analytical corrections for energy and pressure were applied for van der Waals interactions, while the long range electrostatic interactions have been calculated using the Particle Mesh Ewald (PME) method. The simulations were done at $298.15 \mathrm{~K}$, using 
Berendsen and Nosé-Hoover thermostats in sequence with coupling constants of 0.2 and 0.1 ps, respectively.

\section{Results and discussion}

Molecular-level information on interactions between ILs and Langmuir monolayers - used as simplified cell membrane models - has been studied with three lipids. The zwitterionic (i.e. electrically neutral) DPPC was selected because it is one important component of the outer leaflet of the eukaryotic cell membrane. The effect of the concentration of $\left[\mathrm{C}_{6} \mathrm{mim}\right] \mathrm{Cl}$ was studied as it represents the alkyl chain length at which the $\mathrm{EC}_{50}$ values of the imidazolium family suffer a remarkable increase. The effect of the chain length of the alkyl chain of the imidazolium cation was assessed using a series of $\left[\mathrm{C}_{n} \mathrm{mim}\right] \mathrm{Cl}-$ based ILs where the number of carbons of the alkyl chain, $n$, varied between 2 and 10 carbons. The effect of the IL cation and anion was also evaluated, for which $[\mathrm{Chol}] \mathrm{Cl}$ and $\left[\mathrm{C}_{6} \mathrm{mim}\right]\left[\mathrm{BF}_{4}\right]$ were used. In view of what was already known from the literature $9,12,36,37$ about the importance of the alkyl chain length of ILs, $\left[\mathrm{C}_{6} \mathrm{mim}\right] \mathrm{Cl}$ was considered as a reference for this study. DPPG, which is a negatively charged PL, was used to mimic - in a simplified way - the bacterial cell membrane, while cholesterol - the most abundant sterol in eukaryotic cell membranes - was studied owing to its role in structuring and controlling membrane fluidity.

\section{A. Electrically neutral monolayers}

The DPPC isotherm was practically unaffected by $\left[\mathrm{C}_{6} \mathrm{mim}\right] \mathrm{Cl}$ in the subphase for concentrations below its $\mathrm{EC}_{50}$, but it was progressively shifted to larger areas as the concentration increased above $\mathrm{EC}_{50}$, as shown in Fig. 2(a). This shift is kept in the liquid condensed (LC) phase at high surface pressures, suggesting that above $\mathrm{EC}_{50}$ the IL is incorporated in the monolayer and not squeezed out. Since $\mathrm{EC}_{50}$ appears to mark a threshold for the effects to be observed, unless otherwise specified, the concentration of IL used in the subphase in all the experiments was the $\mathrm{EC}_{50}$ of $\left[\mathrm{C}_{6} \mathrm{mim}\right] \mathrm{Cl}$, which is $164.78 \mathrm{mg} \mathrm{L}^{-1}$
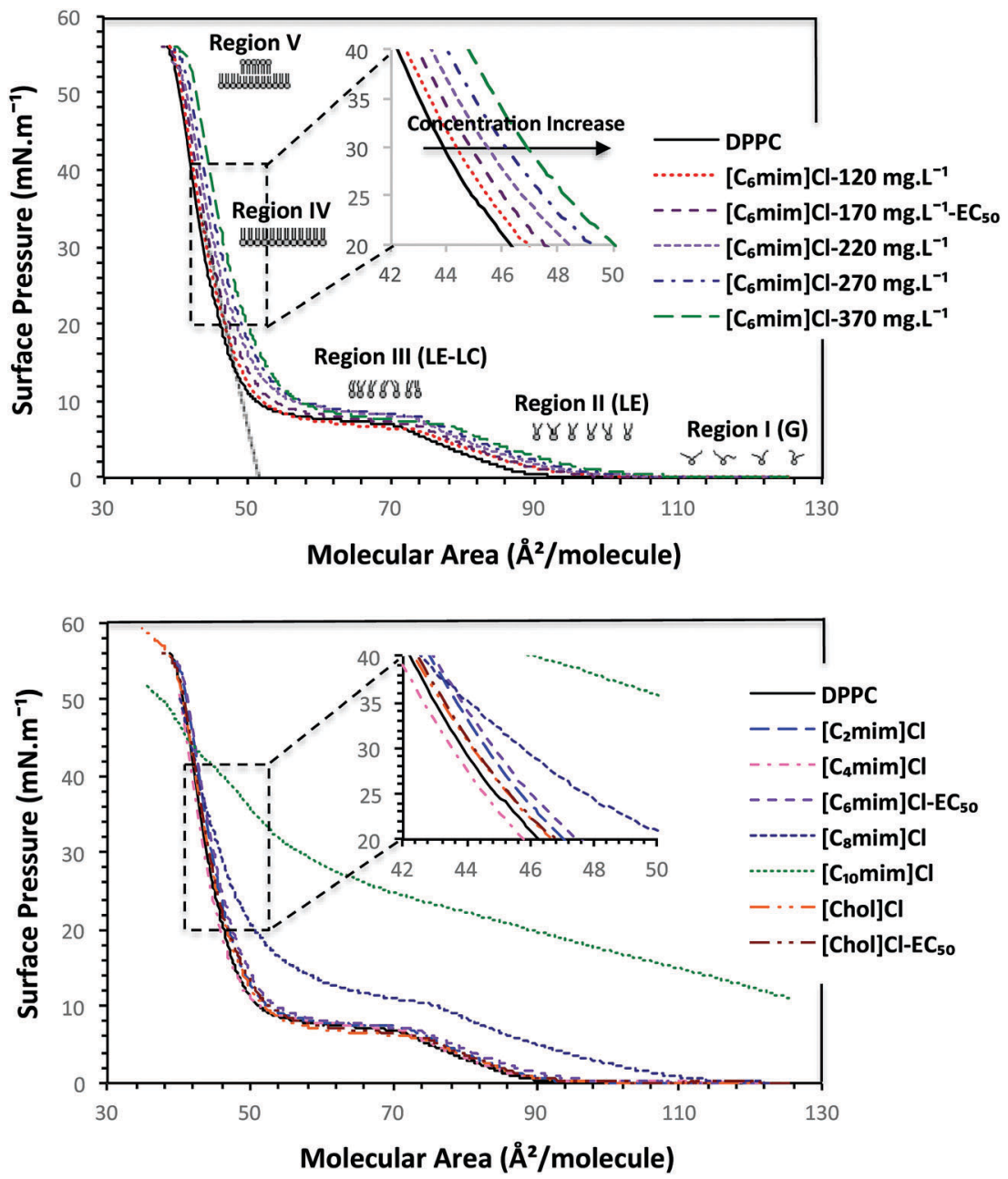

Fig. 2 (a) Surface pressure-area isotherms for pure DPPC monolayers on water and on aqueous solutions of $\left[\mathrm{C}_{6}\right.$ mim] $\mathrm{Cl}_{\text {, at different }}$ concentrations. Inset - expansion of the LE to LC transition; (b) surface pressure-molecular area isotherms for pure DPPC monolayers on water and on aqueous solutions containing $\left[\mathrm{C}_{2} \mathrm{mim}\right] \mathrm{Cl}$, $\left[\mathrm{C}_{4} \mathrm{mim}\right] \mathrm{Cl}$, $\left[\mathrm{C}_{6} \mathrm{mim}\right] \mathrm{Cl},\left[\mathrm{C}_{8} \mathrm{mim}\right] \mathrm{Cl},\left[\mathrm{C}_{10} \mathrm{mim}\right] \mathrm{Cl}$ and $[\mathrm{Chol}] \mathrm{Cl}$, at the concentration of $\left[\mathrm{C}_{6} \mathrm{mim}\right] \mathrm{Cl} \mathrm{EC}{ }_{50}\left(8.13 \times 10^{-4} \mathrm{mM}\right)$ and $[\mathrm{Chol}] \mathrm{Cl}$ at its corresponding $\mathrm{EC}_{50}$. 
$\left(8.13 \times 10^{-4} \mathrm{mM}\right)$. The stability of the monolayer on a $\left[\mathrm{C}_{6} \mathrm{mim}\right] \mathrm{Cl}$ subphase was inferred by the negligible changes in the isotherms in three consecutive isocycles shown in Fig. SI.2 in the ESI. $\dagger$ The importance of the alkyl length of ILs on the surface pressure isotherms of a DPPC monolayer is illustrated in Fig. 2(b). While practically no effect is detected for $\left[\mathrm{C}_{2} \mathrm{mim}\right] \mathrm{Cl}$ and $\left[\mathrm{C}_{4} \mathrm{mim}\right] \mathrm{Cl}$, large shifts are observed for $\left[\mathrm{C}_{8} \mathrm{mim}\right] \mathrm{Cl}$ and $\left[\mathrm{C}_{10} \mathrm{mim}\right] \mathrm{Cl}$. In fact, the latter induced an entirely different isotherm. Therefore, the minimum chain length for imidazolium ILs to have a significant effect on DPPC is six carbons. In order to further assess the effect of the cation, $[\mathrm{Chol}] \mathrm{Cl}$, an IL from the cholinium family with a very distinct cation, was used at two concentrations: the $\mathrm{EC}_{50}$ of $\left[\mathrm{C}_{6} \mathrm{mim}\right] \mathrm{Cl}$ as in the previous cases and at its own $\mathrm{EC}_{50}$. The choline cation had negligible effect on the DPPC monolayer, even at a concentration of $469 \mathrm{mg} \mathrm{L}^{-1}$, i.e. its own $\mathrm{EC}_{50}$ (see Fig. 2a). This supports the notion that the toxicity mechanism of [Chol]Cl is different from the other compounds and not related to interactions with the cell membrane. ${ }^{38-40}$

For the study of the impact of the anion, only ILs with $n$ equal to 6 or 8 were considered and the effect of $[\mathrm{BF} 4]^{-}$was compared with that of $\mathrm{Cl}^{-}$. The results in Fig. 3 are consistent with the higher toxicity of hydrophobic species. ${ }^{12}$ When the alkyl chain has 6 carbons, the effect of $\left[\mathrm{BF}_{4}\right]^{-}$in comparison with $\mathrm{Cl}^{-}$is only slightly noticeable in the LE and LE-LC regions. The main difference registered is when $n=8$, where ILs containing the more hydrophobic $\left[\mathrm{BF}_{4}\right]^{-}$ions induced a larger shift in the isotherm than the $\mathrm{Cl}^{-}$containing IL. Interestingly, despite the larger effect in the LE region and the suppression of the LE-LC region, the isotherm in the presence of $\left[\mathrm{C}_{8} \mathrm{mim}\right]\left[\mathrm{BF}_{4}\right]$ coincides with that of neat DPPC at very high surface pressures suggesting that ILs with more hydrophobic anions seem to be squeezed out of the monolayer.

The pressure-area isotherms provide macroscopic thermodynamic information, but to obtain information at a lower length scale, specifically at the mesoscopic scale, Brewster angle microscopy (BAM) was used. As BAM is very sensitive to the rate of compression of the monolayer, it is not easy to extract exact information on the morphology (size and shape) of domains formed at the air-water interface. Yet, when experimental conditions are very controlled as in the present case, BAM can provide a clear picture of the interactions between the monolayer and substances in the aqueous phase. Fig. 4 shows the micrographs of monolayers of DPPC collected on pure water and on aqueous solutions of $\left[\mathrm{C}_{4} \mathrm{mim}\right] \mathrm{Cl},\left[\mathrm{C}_{6} \mathrm{mim}\right] \mathrm{Cl}$, $\left[\mathrm{C}_{8} \mathrm{mim}\right] \mathrm{Cl}$ and $[\mathrm{Chol}] \mathrm{Cl}$ at the same barrier position, i.e. at the same value of area per molecule $\left(83 \AA^{2}\right)$. This procedure was selected due to the different effects that the ILs cause on the DPPC monolayer corresponding to distinct values of surface pressure and regions of the $\pi-A$ isotherm. At this specific value of area per molecule, the DPPC monolayer on pure water hardly reflects any light. However, in the presence of $\left[\mathrm{C}_{4} \mathrm{mim}\right] \mathrm{Cl}$ the characteristic DPPC domains have developed from the asymmetric "bean" structures typical of DPPC on pure water (shown in the inset which is only detected at higher values of area per molecule), ${ }^{41}$ yet, the number of domains is quite high, their morphology is rather irregular and their size is small. For $\left[\mathrm{C}_{6} \mathrm{mim}\right] \mathrm{Cl}$, although the number of domains is smaller than for $n=4$, the characteristic trilobed DPPC domains are clearly observed. In turn, for $n=8$, the monolayer is rather heterogeneous and the morphology of the domains observed suggests that for ILs with longer alkyl chains, domains that nucleated in close proximity bridge, yielding rather complex patterns. In order to evaluate the effect of interactions between DPPC headgroups and IL cations the compression of a DPPC monolayer on an aqueous solution of [Chol] $\mathrm{Cl}$ was also visualized. The results obtained indicate that at low compression interactions between the monolayer and ILs are governed by electrostatic interactions between the head group of the phospholipid and the charged moiety of the ILs, especially in the case of $\left[\mathrm{C}_{4} \mathrm{mim}\right] \mathrm{Cl}$ and $[\mathrm{Chol}] \mathrm{Cl}$. For ILs with longer alkyl chains the hydrophobic tails seem to play a determinant role in the

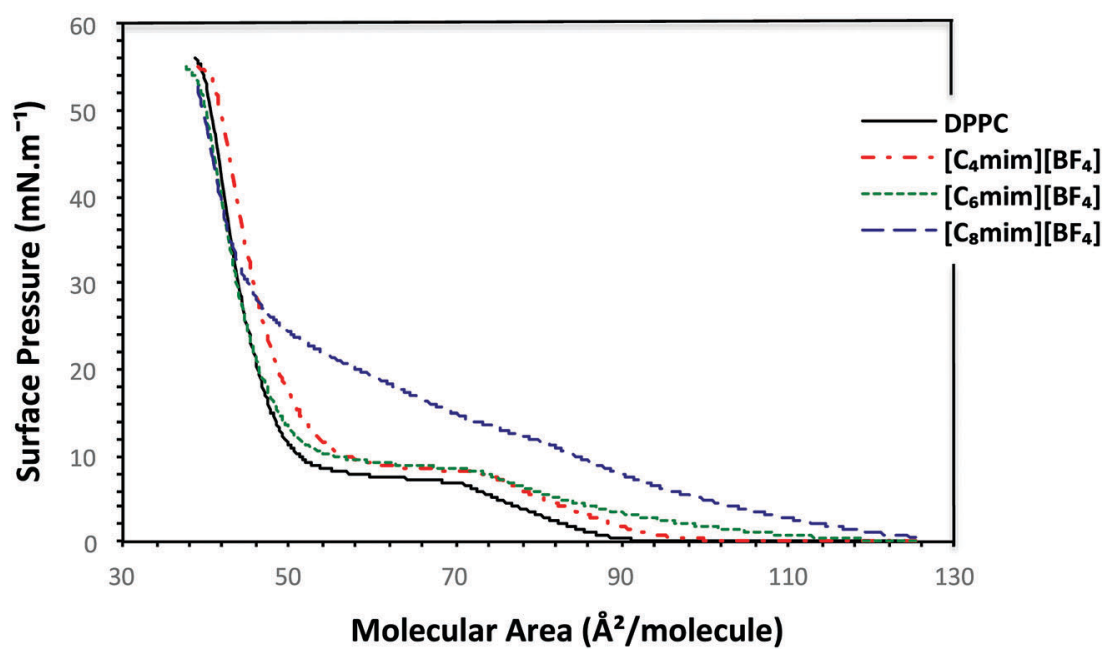

Fig. 3 Surface pressure-area isotherms for pure DPPC monolayers on water and on aqueous solutions of $\left[\mathrm{C}_{6} \mathrm{mim}\right] \mathrm{Cl}_{\text {, }}\left[\mathrm{C}_{6} \mathrm{mim}\right]\left[\mathrm{BF}{ }_{4}\right],\left[\mathrm{C}_{8} \mathrm{mim}\right] \mathrm{Cl}$, and $\left[\mathrm{C}_{8} \mathrm{mim}\right]\left[\mathrm{BF}_{4}\right]$, at the concentration of $\left[\mathrm{C}_{6} \mathrm{mim}\right] \mathrm{Cl} \mathrm{EC}_{50}\left(8.13 \times 10^{-4} \mathrm{mM}\right)$. 


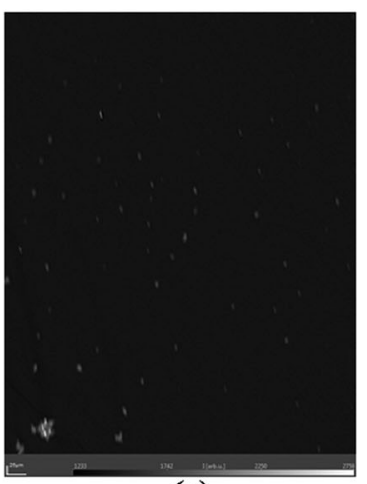

(a)

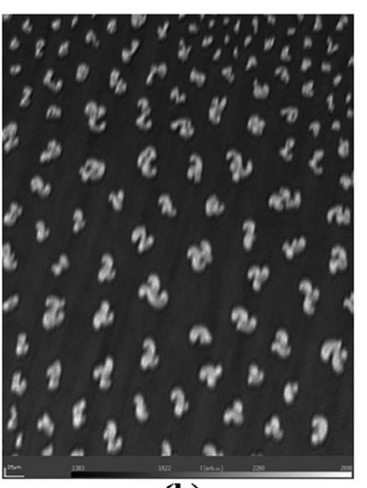

(b)

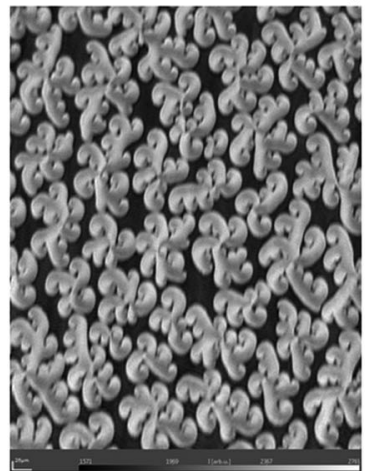

(c)

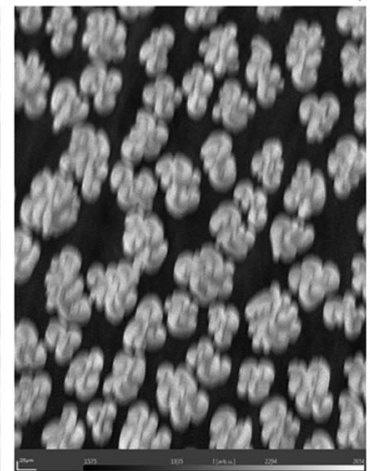

(d)

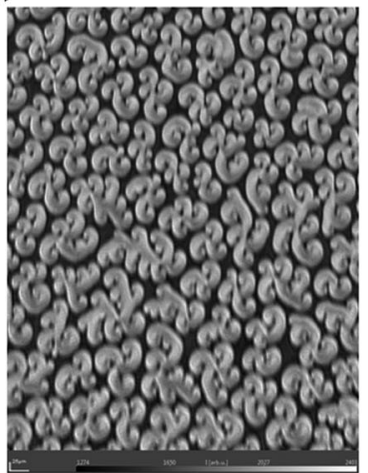

(e)

Fig. 4 BAM images of DPPC collected on (a) water, and aqueous solutions of (b) $\left[\mathrm{C}_{4} \mathrm{mim}\right] \mathrm{Cl}$, (c) $\left[\mathrm{C}_{6} \mathrm{mim}\right] \mathrm{Cl}$, (d) $\left[\mathrm{C}_{8} \mathrm{mim}\right] \mathrm{Cl}$ and (e) $[\mathrm{Chol}] \mathrm{Cl}$ at: $83 \AA^{2}$. IL concentrations in the subphase correspond to the $\mathrm{EC}_{50}$ of $\left[\mathrm{C}_{6} \mathrm{mim}\right] \mathrm{Cl}\left(8.13 \times 10^{-4} \mathrm{mM}\right)$.

organization of the domains. Changes in morphology at different levels of compression were studied with a set of images taken at three critical regions of the isotherm, i.e. right at the beginning of the LE region, in the LE-LC transition region and in the LC region. Fig. SI.3 (ESI $\dagger$ ) shows the images for the most representative cases, i.e. pure water, $\left[\mathrm{C}_{6} \mathrm{mim}\right] \mathrm{Cl}$ and $[\mathrm{Chol}] \mathrm{Cl}$. The presence of imidazolium type ILs seems to accelerate the formation of domains when compared to what is observed in the case of pure water. Moreover, the domains tend to be denser and multilobed. However, in the presence of [Chol] $\mathrm{Cl}$, the formation of the trilobed domain motif initially is not regular and seems to be slower. Yet, once they are formed the domains' morphology seems to persist for a longer period than in the case of imidazolium type ILs, suggesting that interactions with the head group affect the nucleation and growth of domains. A similar effect was observed for $\left[\mathrm{C}_{4} \mathrm{mim}\right] \mathrm{Cl}$ and $\left[\mathrm{C}_{8} \mathrm{mim}\right] \mathrm{Cl}$. Representative images for these two ILs are shown in Fig. SI.4 and SI.5 (ESI $\dagger$ ). Generally, in the LC region the domains coalesced and formed a compact but textured monolayer, especially those on aqueous solutions of ILs, indicating that ILs' molecules may have been incorporated in the phospholipid monolayer. Furthermore, isocycles of DPPC monolayers on aqueous $\left[\mathrm{C}_{6} \mathrm{mim}\right] \mathrm{Cl}$ show the morphology of domains is not reversible which is in agreement with the literature. ${ }^{41}$ See Fig. SI.6(b) and those on pure water in SI.6(a) (ESI $\dagger$ ).

The PM-IRRAS spectra taken at the air/aqueous interface were used to monitor the imidazolium-based ILs' interaction with both monolayers, DPPC and DPPG, separately. Besides the cationic imidazolium, the effects of alkyl chain length, $\mathrm{C}_{2}-\mathrm{C}_{10}$, were also analysed. The packing of lipid chains in Langmuir monolayers was investigated by monitoring the methylene stretching vibrations. ${ }^{42,43}$ The spectrum for pure DPPC recorded at $30 \mathrm{mN} \mathrm{m}^{-1}$ in Fig. 5a shows asymmetric and symmetric C-H vibration bands at 2920 and $2850 \mathrm{~cm}^{-1}$, respectively. With addition of ILs, a slight shift of the symmetric $\mathrm{CH}_{2}$ stretching band was observed, as shown in Fig. 5a and in the ESI $\dagger$ (Fig. SI.7), which depended on the number of carbon atoms in the alkyl chain $\left(\mathrm{C}_{2}\right.$ to $\left.\mathrm{C}_{10}\right)$. The ratio of the relative band intensities, $\nu_{\mathrm{a}}\left(\mathrm{CH}_{2}\right) / \nu_{\mathrm{s}}\left(\mathrm{CH}_{2}\right)$, was employed to determine the degree of order of the lipid hydrocarbon chains within the monolayer. ${ }^{44,45}$ Fig. $5 \mathrm{~b}$ indicates that the ratio increased from 0.4 to 0.78 with the increasing number of carbon atoms. Therefore, ILs induce an increase in the order of hydrocarbon chains in the DPPC monolayer, which is particularly significant for $n \geq 4$.

The hydration of the carbonyl group in the head group can be proved by analyzing the $\nu(\mathrm{C}=\mathrm{O})$ band, which appears at $1741 \mathrm{~cm}^{-1}$ for pure DPPC. ${ }^{4,45}$ When increased concentrations of ILs are added to the subphase, this band shifts from 1740 to $1712 \mathrm{~cm}^{-1}$, as shown in Fig. $6 \mathrm{a}$ and b. Hence, as the number of carbon atoms in the alkyl chain increases, the environment around the $\mathrm{C}=\mathrm{O}$ group becomes increasingly hydrated with hydrogen bonds between ILs and DPPC head groups. ${ }^{46}$

MD simulations of DPPC monolayers at the surface of aqueous solutions of $\left[\mathrm{C}_{n} \mathrm{mim}\right] \mathrm{Cl}$, for $n=2,4,6,8$ and 10 , were performed at 298.15 K and three surface densities: $87 \AA^{2}$ per molecule, $64 \AA^{2}$ per molecule and $49 \AA^{2}$ per molecule, i.e., at the beginning, half way and at the end of the LE-LC transition plateau, respectively. 

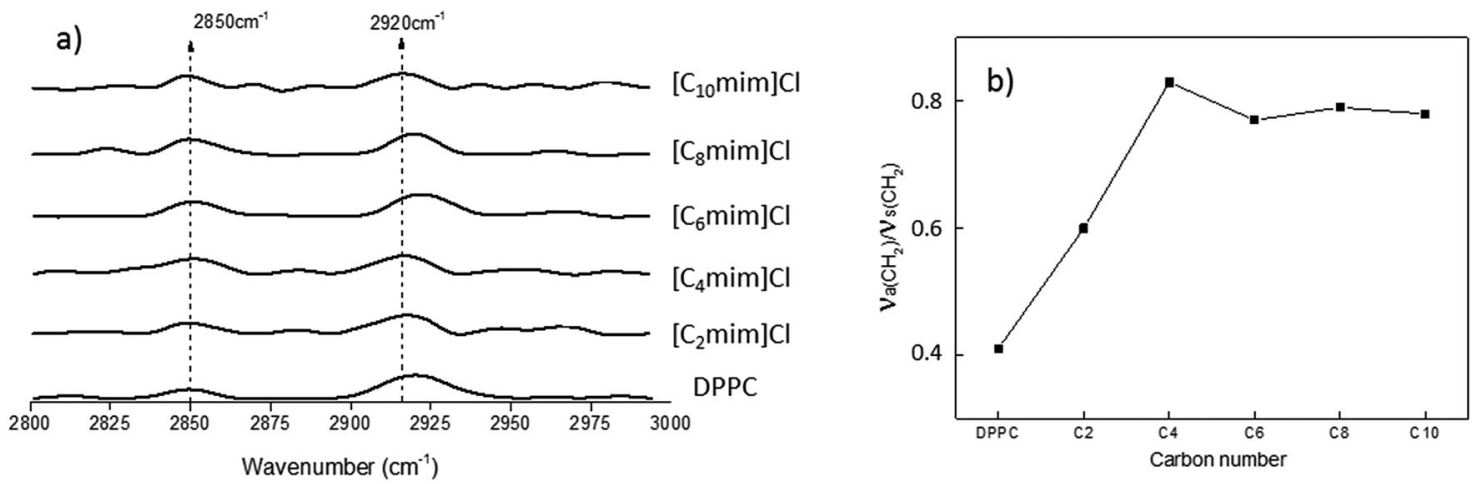

Fig. 5 PM-IRRAS spectra in the region of the methylene stretching bands $\left(2800-3000 \mathrm{~cm}^{-1}\right)$ for a pure DPPC monolayer (-) spread on a water subphase, and on aqueous solutions of ILs (a). Ratio of relative band intensities, $\nu_{\mathrm{a}}\left(\mathrm{CH}_{2}\right) / \nu_{\mathrm{s}}\left(\mathrm{CH}_{2}\right)$ (b).
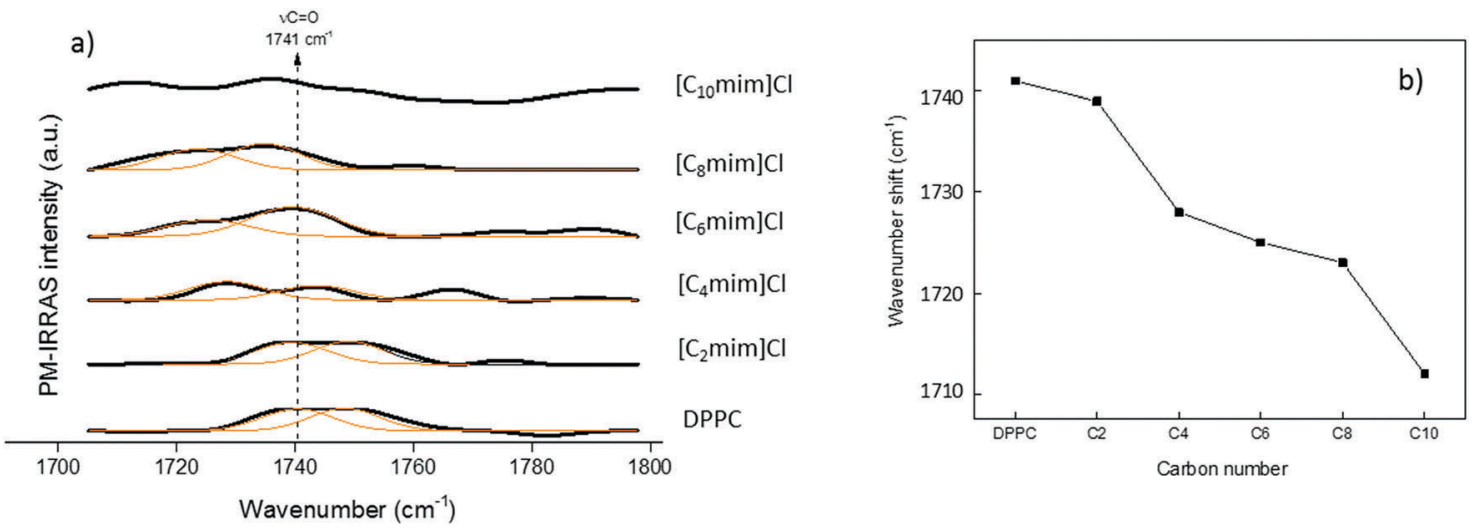

Fig. 6 PM-IRRAS spectra in the region of the carbonyl stretching bands $\left(1800-1700 \mathrm{~cm}^{-1}\right)$ for a pure DPPC monolayer spread on a water subphase, and on aqueous solutions of ILS (a). Wavenumber shift of the vibration bands as a function of the number of carbons in the alkyl chain of ILs (b).

In Fig. 7 the numerical density profiles of DPPC and the five ILs along the $z$ axis of the simulation boxes are shown. Comparing the results at the three surface densities, a first general conclusion can be immediately extracted: at the lower surface density, $87 \AA^{2}$ per molecule, although the ILs remain mostly in solution, extensive insertion of all cations within the monolayer is observed. This tendency to penetrate the monolayer is greatly reduced at $64 \AA^{2}$ per molecule and at $49 \AA^{2}$ per molecule is practically absent. These observations suggest that in the "real system", penetration of the ILs in the DPPC
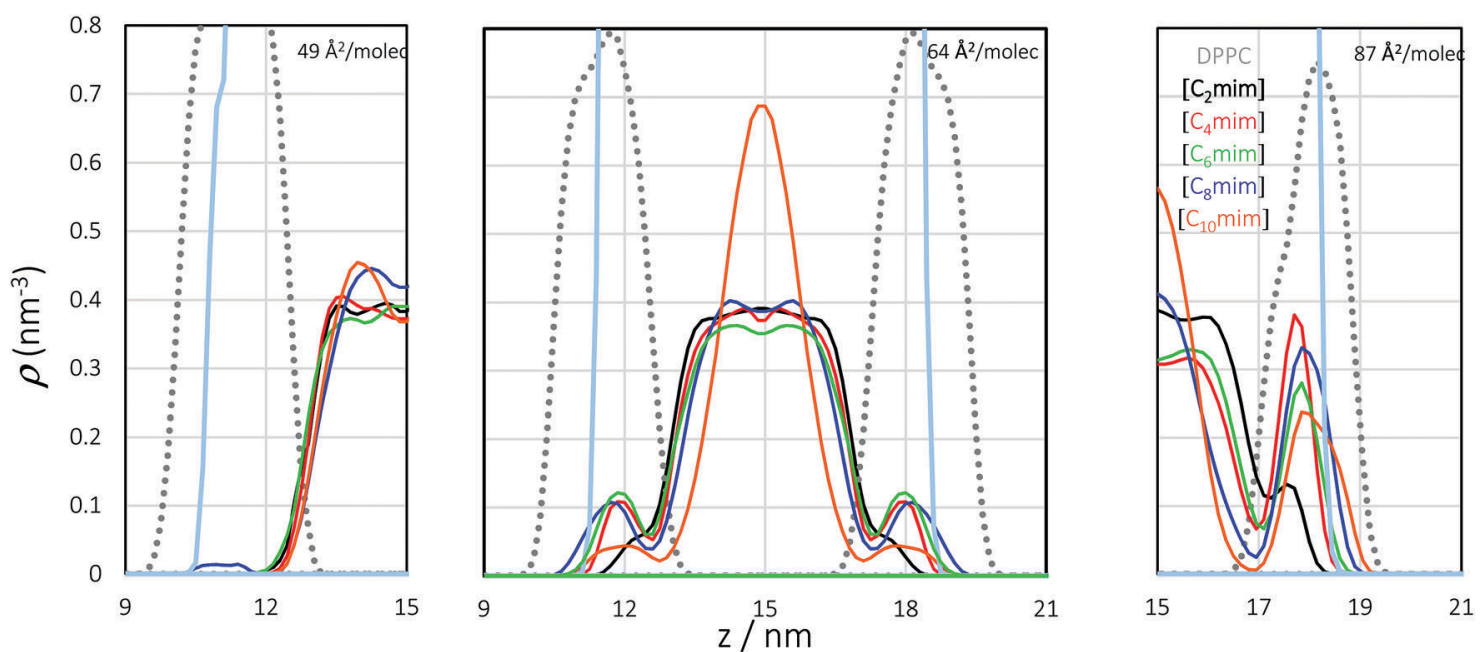

Fig. 7 Numerical density profiles for the five ILs along the monolayer normal coordinate $(z)$ at $87 \AA^{2}$ per molecule, $64 \AA^{2}$ per molecule and $49 \AA^{2}$ per molecule. 

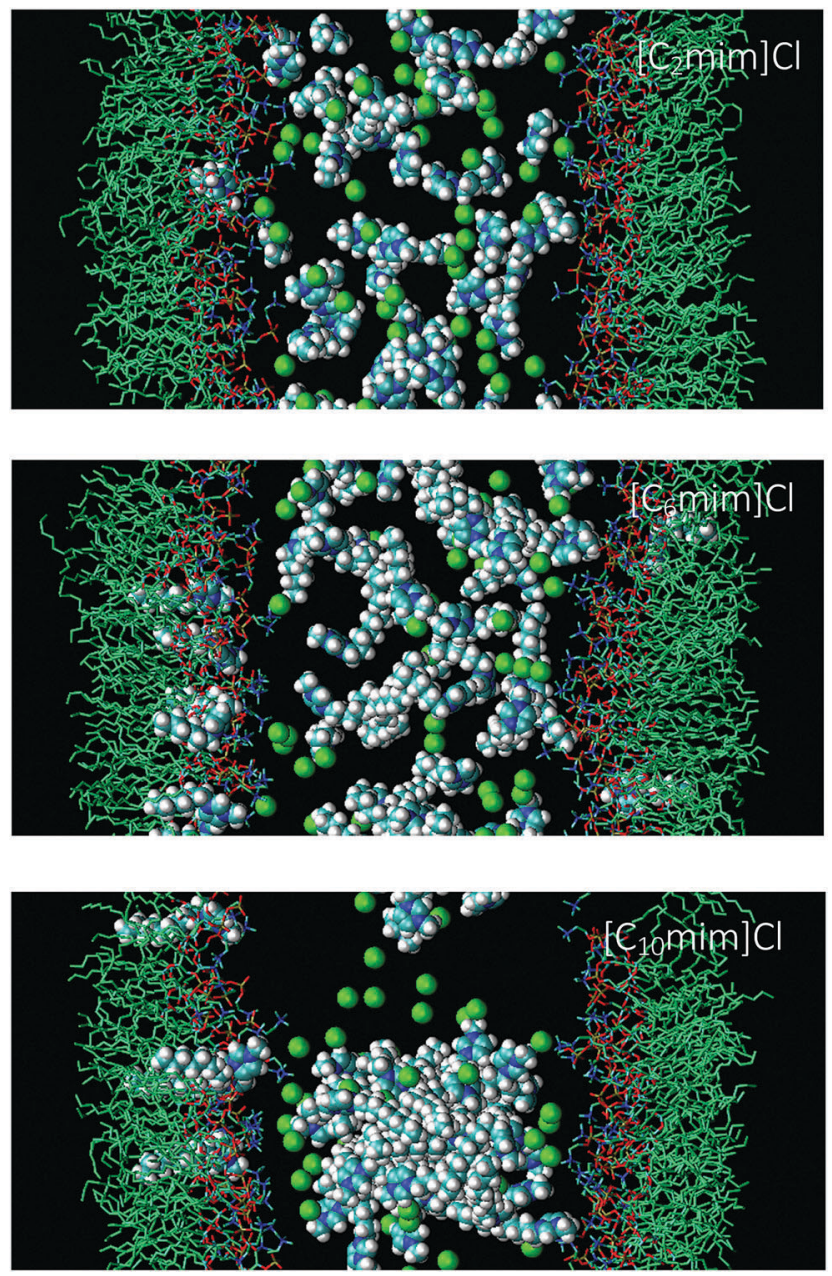

Fig. 8 Simulation snapshots for the $\left[\mathrm{C}_{2} \mathrm{mim}\right] \mathrm{Cl},\left[\mathrm{C}_{6} \mathrm{mim}\right] \mathrm{Cl}$ and $\left[\mathrm{C}_{10} \mathrm{mim}\right] \mathrm{Cl}$ systems, at $64 \AA^{2}$ per molecule. monolayer occurs essentially during the initial stages of the compression, while the surface density is still low.

The simulation results also show that, for all surface densities, but in particular at $64 \AA^{2}$ per molecule, the tendency to penetrate the DPPC monolayer is almost negligible for $\left[\mathrm{C}_{2} \mathrm{mim}\right] \mathrm{Cl}$, increasing distinctively as the IL side chain gets longer. However, the insertion of the longest $\mathrm{IL},\left[\mathrm{C}_{10} \mathrm{mim}\right] \mathrm{Cl}$, seems weaker than that of the shorter ILs, which can be due to the formation of aggregates (micelles) in the aqueous media, that reduce the number of free IL available to interact with the monolayer. This is illustrated in Fig. 8 where matching simulation box snapshots for $\left[\mathrm{C}_{2} \mathrm{mim}\right] \mathrm{Cl},\left[\mathrm{C}_{6} \mathrm{mim}\right] \mathrm{Cl}$ and $\left[\mathrm{C}_{10} \mathrm{mim}\right] \mathrm{Cl}$ are shown. The existence of a large aggregate of $\left[\mathrm{C}_{10} \mathrm{mim}\right] \mathrm{Cl}$ is apparent.

The average location and relative orientation of the IL within the DPPC monolayer can be inferred from the density profiles of selected atoms, as shown in Fig. 9 for $\left[\mathrm{C}_{2} \mathrm{mim}\right] \mathrm{Cl},\left[\mathrm{C}_{6} \mathrm{mim}\right] \mathrm{Cl}$ and $\left[\mathrm{C}_{10} \mathrm{mim}\right] \mathrm{Cl}$ at $64 \AA^{2}$ per molecule: the cations inserted in the monolayer stretch perpendicularly to the plane of the interface, with the imidazolium ring lying close to the charged groups of the phospholipids, while the terminal $\mathrm{CH}_{3}$ groups penetrate deep into the DPPC chain region. The imidazolium ring seems to be on average closer to the phosphate group than to either the cholinium $\mathrm{N}\left(\mathrm{CH}_{3}\right)^{+}$or glycerol's oxygen atoms, as could be expected from electrostatic considerations.

Radial distribution functions (rdf) between imidazolium and DPPC atoms corroborate this relative position. In Fig. 10, rdf of ring imidazolium carbon atoms around DPPC phosphorus and nitrogen are presented for all the systems studied. The first peaks in the case of phosphorus are located at distances considerably shorter than the ones from nitrogen. In the first case, the peak intensities follow an order related to the insertion capacity of the IL, which in turn is a function of the chain length
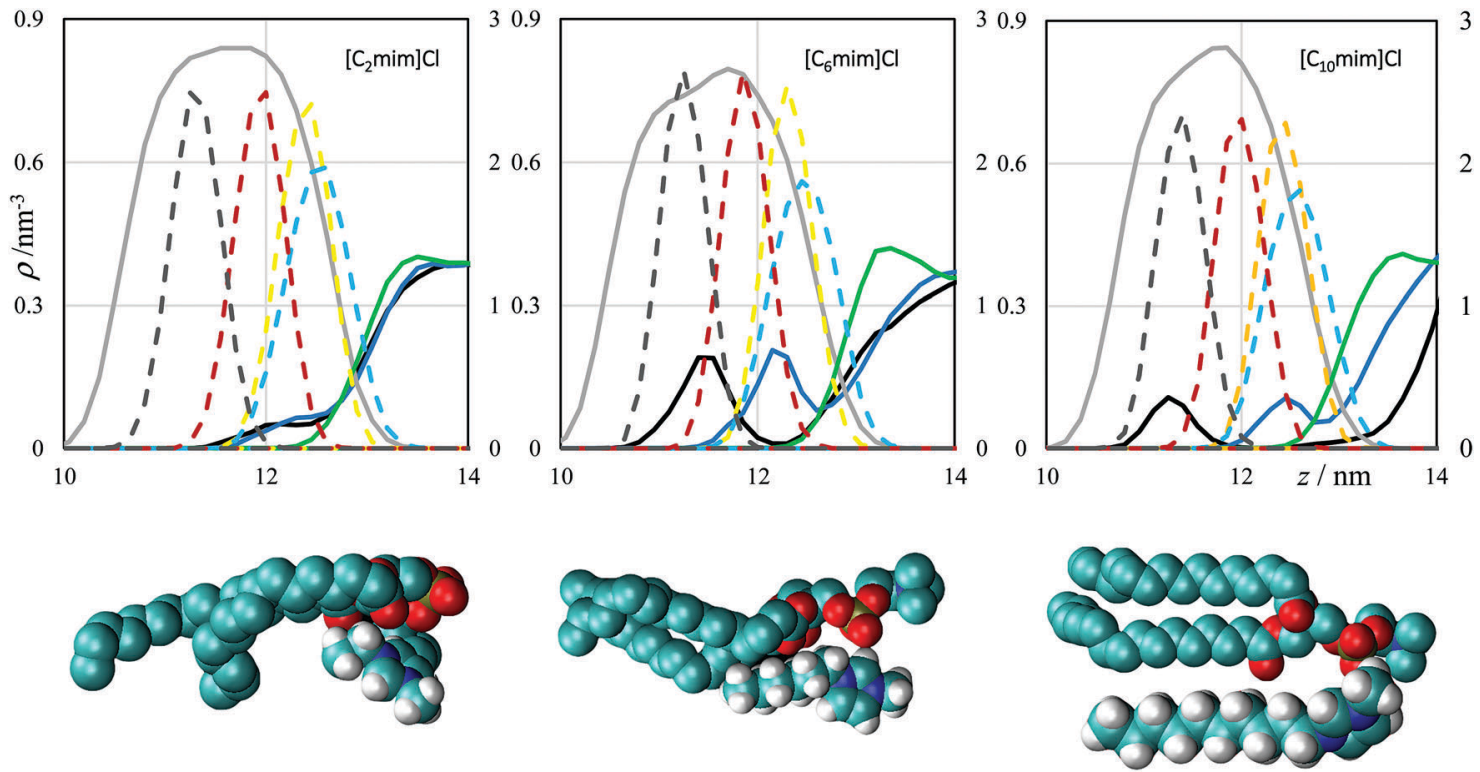

Fig. 9 Density profiles for selected atoms of $\left[\mathrm{C}_{2} \mathrm{mim}\right] \mathrm{Cl},\left[\mathrm{C}_{6} \mathrm{mim}\right] \mathrm{Cl},\left[\mathrm{C}_{10} \mathrm{mim}\right] \mathrm{Cl}$ and DPPC at $64 \AA^{2}$ per molecule. IL: $\mathrm{N}$ atom on mim ring (solid blue), terminal $\mathrm{C}$ atom on side chain (solid black); DPPC: $\mathrm{N}$ atom (dashed blue), $\mathrm{P}$ atom (dashed yellow), carbonyl $\mathrm{C}$ atom on sn2 chain (dashed red), middle $\mathrm{C}$ atom on acyl chain (dashed grey) and DPPC molecule (solid green). 


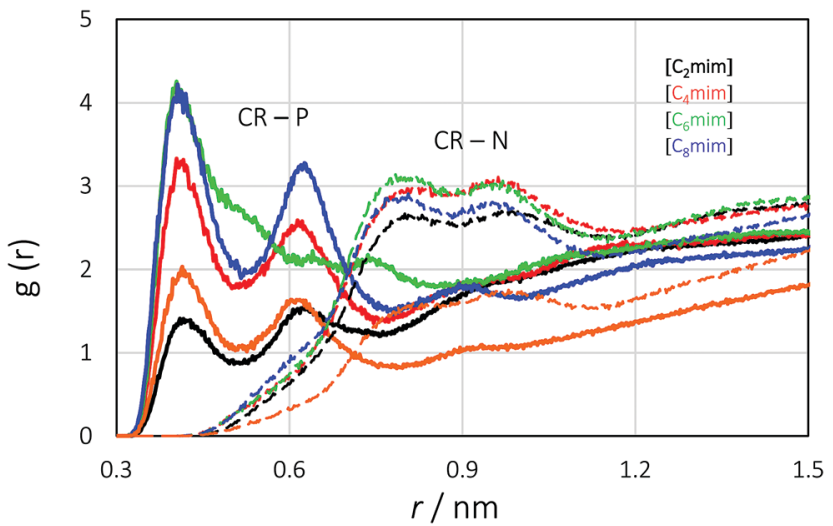

Fig. 10 Radial distribution functions of imidazolium ring CR carbon atoms around DPPC phosphorus and DPPC nitrogen.

and the tendency to form nano-aggregates in aqueous solution. Also from Fig. 8 it can be seen that the $\mathrm{Cl}^{-}$anion hardly penetrates the DPPC monolayer, remaining essentially solvated in solution.
Cholesterol. Considering the biological relevance of cholesterol in terms of structuring and controlling the fluidity of eukaryotic cell membranes and the fact that it is also a neutral molecule, $\pi$ versus $A$ isotherms were performed to evaluate the effects of alkyl chain size. Fig. 11a shows negligible effects of $\left[\mathrm{C}_{n} \mathrm{mim}\right] \mathrm{Cl}$ for $n<6$, as for DPPC monolayers. The isotherms are shifted toward larger areas for increasing alkyl chain lengths, with the isotherm recorded in the presence of $\left[\mathrm{C}_{10} \mathrm{mim}\right] \mathrm{Cl}$ being entirely different from that obtained in the presence of pure water. Imidazole did not interact with the cholesterol monolayer probably because cholesterol molecules are not charged and imidazole is not sufficiently hydrophobic to establish interactions with it. Likewise, the presence of [Chol] $\mathrm{Cl}$ in the aqueous subphase, at least at this concentration, does not affect the cholesterol monolayer. The effect of the hydrophobicity of the anion is illustrated in Fig. $11 \mathrm{~b}$ and it is clear that when $\left[\mathrm{BF}_{4}\right]^{-}$was used, the effect on the cholesterol monolayer was more significant than that of its $\mathrm{Cl}^{-}$counterpart, especially when the number of carbons in the alkyl chain was 8 .
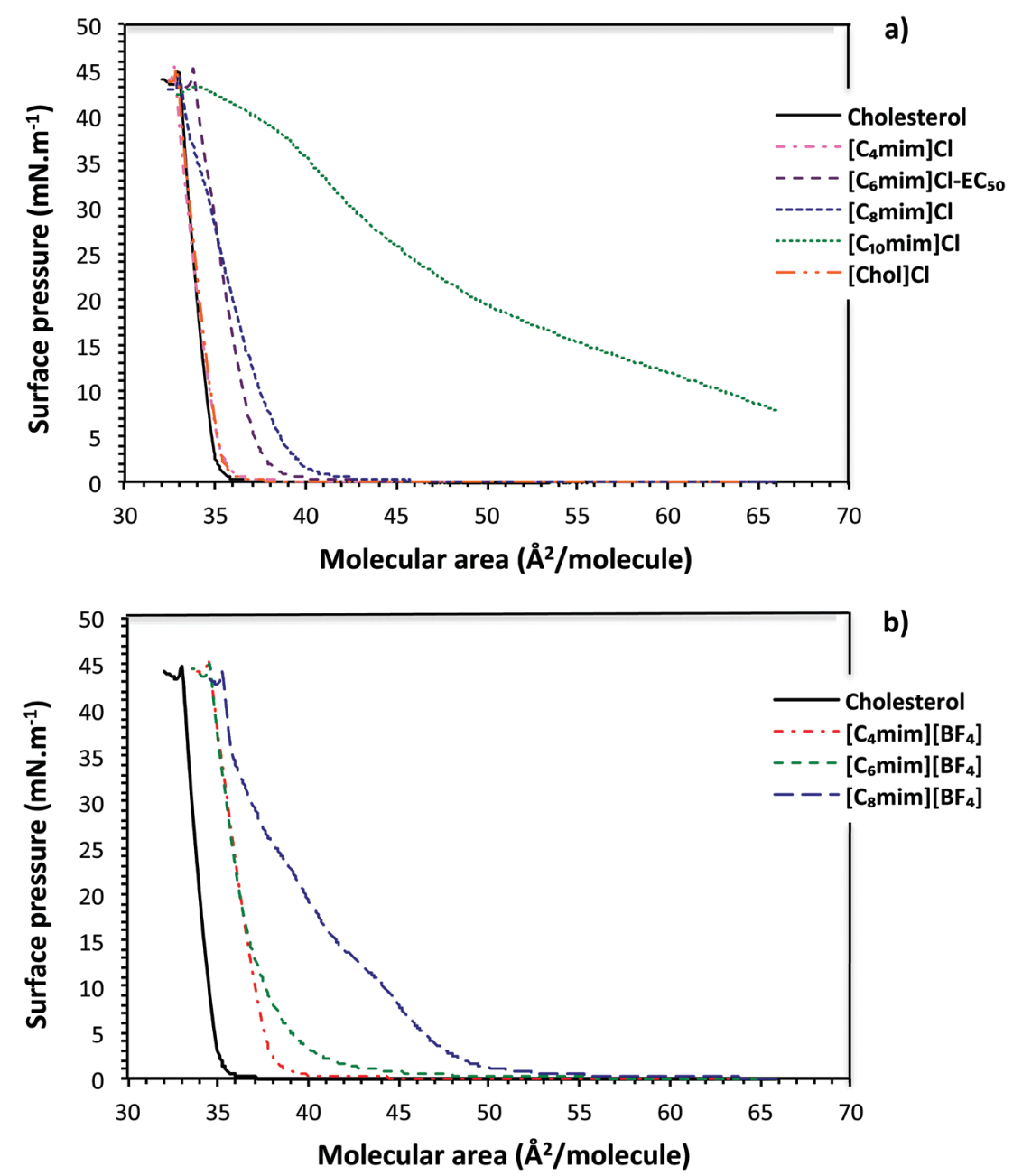

Fig. 11 (a) Surface pressure-molecular area isotherms of cholesterol monolayers on pure water and on aqueous solutions containing, $\left[\mathrm{C}_{4}\right.$ mim $] \mathrm{Cl}_{\text {, }}$ $\left[\mathrm{C}_{6} \mathrm{mim}\right] \mathrm{Cl},\left[\mathrm{C}_{8} \mathrm{mim}\right] \mathrm{Cl},\left[\mathrm{C}_{10} \mathrm{mim}\right] \mathrm{Cl}$ and $[\mathrm{Chol}] \mathrm{Cl}$, at the concentration of $\left[\mathrm{C}_{6} \mathrm{mim}\right] \mathrm{Cl} \mathrm{EC}_{50}\left(8.13 \times 10^{-4} \mathrm{mM}\right)$; (b) surface pressure-area isotherms of cholesterol monolayers on pure water and on aqueous solutions containing $\left[\mathrm{C}_{4} \mathrm{mim}\right]\left[\mathrm{BF}_{4}\right],\left[\mathrm{C}_{6} \mathrm{mim}\right]\left[\mathrm{BF}_{4}\right]$ and $\left[\mathrm{C}_{8} \mathrm{mim}\right]\left[\mathrm{BF}_{4}\right]$ at $\left[\mathrm{C}_{6} \mathrm{mim}\right] \mathrm{Cl}_{\mathrm{B}} \mathrm{EC_{50 }}$ $\left(8.13 \times 10^{-4} \mathrm{mM}\right)$ 


\section{B. Negatively charged monolayers}

The IL molecules had a much greater effect on DPPG monolayers owing to their charged nature. Fig. 12a shows that all ILs had a major effect on the monolayer, including [Chol]Cl, $\left[\mathrm{C}_{2} \mathrm{mim}\right] \mathrm{Cl}$ and $\left[\mathrm{C}_{4} \mathrm{mim}\right] \mathrm{Cl}$, which did not affect DPPC monolayers. As the number of carbons in the alkyl chain increases there is practically complete disruption of the DPPG monolayer. Similarly to the case of the neutral phospholipid DPPC, the IL containing the more hydrophobic anion $\left[\mathrm{BF}_{4}\right]^{-}$also caused larger changes in the DPPG monolayer as illustrated in Fig. 12b.

The BAM images in Fig. 13 for DPPG monolayers all taken at an area per molecule of $94 \AA^{2}$ on pure water indicate that at low compression several irregular branch-like domains appear which are interconnected across the interface as already reported. ${ }^{41}$ The monolayers in the presence of $\left[\mathrm{C}_{4} \mathrm{mim}\right] \mathrm{Cl}$ and $\left[\mathrm{C}_{6} \mathrm{mim}\right] \mathrm{Cl}$ formed granular domains all over the interface, whilst in the case of $[\mathrm{Chol}] \mathrm{Cl}$ fingered domains are observed. Curiously, the morphology of the domains formed in the presence of $\left[\mathrm{C}_{8} \mathrm{mim}\right] \mathrm{Cl}$ is completely distinct. Indeed, for $n=8$ even when a lower concentration of the IL was used a similar result was observed (data not shown). These results indicate that in the presence of ILs domains are formed very quickly and adopt rather distinct morphologies depending on the type of cation, possibly due to strong electrostatic interactions with the head group of DPPG. Nevertheless, the role of the hydrophobic tails is equally striking, especially in the case of $\left[\mathrm{C}_{8} \mathrm{mim}\right] \mathrm{Cl}$. As for DPPC, a set of images taken at three critical regions of the isotherm of a DPPG monolayer on pure water, $\left[\mathrm{C}_{6} \mathrm{mim}\right] \mathrm{Cl}$ and $[\mathrm{Chol}] \mathrm{Cl}$ is presented in Fig. SI.8 (ESI $\dagger$ ). Interestingly, for [Chol] Cl in the aqueous subphase, the shape of DPPG domains was rather distinct, and kept changing until rectangular like domains were formed as the barriers were closing. In turn, when the LC region was reached, the domains in the presence of water or aqueous solutions of $\left[\mathrm{C}_{6} \mathrm{mim}\right] \mathrm{Cl}$ are almost compact but those in the presence of aqueous solutions of [Chol]Cl still have empty spaces. As the barriers were further closed, the domains coalesced yielding compact and reasonably homogeneous monolayers in the case of pure water and of $\left[\mathrm{C}_{6} \mathrm{mim}\right] \mathrm{Cl}$. However, for [Chol]Cl coalescence of the domains seems to be prevented as the platelets formed are still observed, pointing to
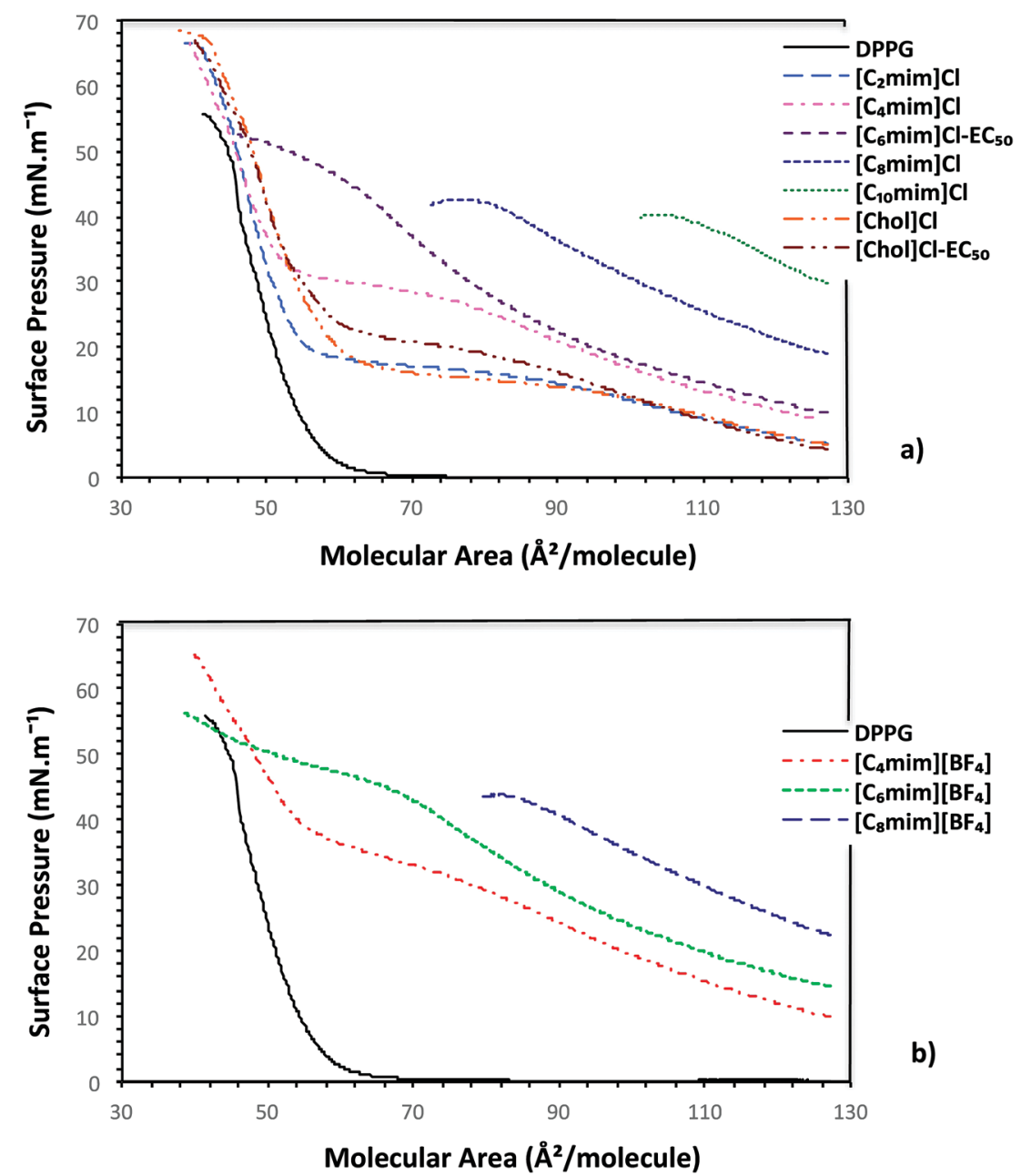

Fig. 12 (a) Pressure-area isotherms for pure DPPG monolayers on water and on aqueous solutions of different ILs of the [ $\mathrm{C}_{n}$ mim] Cl type, and [Chol] $\mathrm{Cl}$ at $\left[\mathrm{C}_{6} \mathrm{mim}\right] \mathrm{Cl} \mathrm{EC}_{50}\left(8.13 \times 10^{-4} \mathrm{mM}\right)$ and [Chol] $\mathrm{Cl}$ at its own $\mathrm{EC}_{50}$; (b) surface pressure-area isotherms for pure DPPG monolayers on water and on aqueous solutions of $\left[\mathrm{C}_{6} \mathrm{mim}\right] \mathrm{Cl},\left[\mathrm{C}_{6} \mathrm{mim}\right]\left[\mathrm{BF}_{4}\right],\left[\mathrm{C}_{8} \mathrm{mim}\right] \mathrm{Cl}$ and $\left[\mathrm{C}_{8} \mathrm{mim}\right]\left[\mathrm{BF}_{4}\right]$ at the concentration of $\left[\mathrm{C}_{6} \mathrm{mim}\right] \mathrm{Cl}_{\mathrm{E}} \mathrm{EC} \mathrm{C}_{50}\left(8.13 \times 10^{-4} \mathrm{mM}\right)$. 


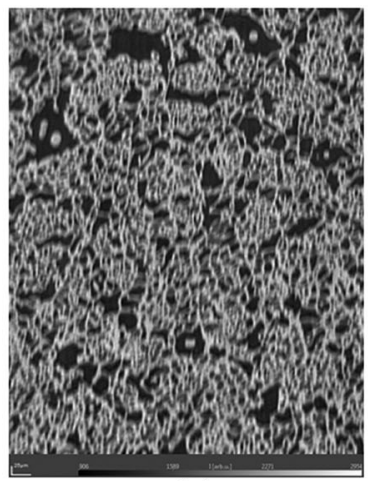

(a)

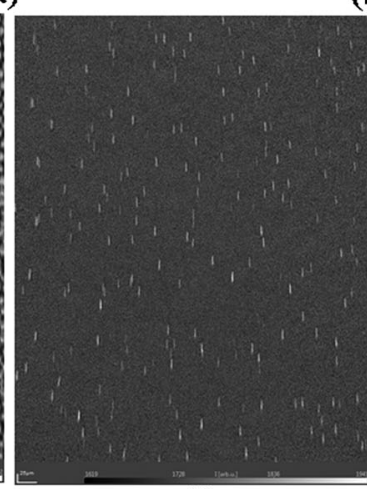

(d)

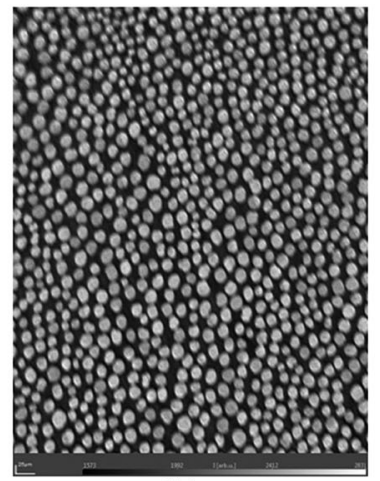

(b)

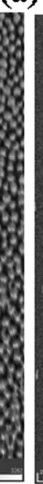

(c)

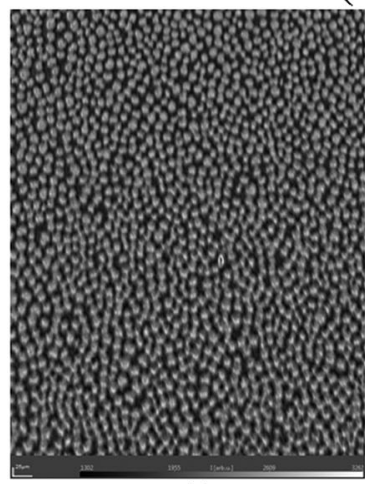

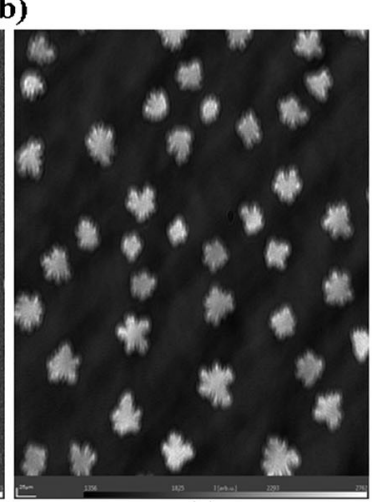

(e)

Fig. 13 BAM images of DPPG collected on (a) water, and aqueous solutions of (b) $\left[\mathrm{C}_{4} \mathrm{mim}\right] \mathrm{Cl}$, (c) $\left[\mathrm{C}_{6} \mathrm{mim}\right] \mathrm{Cl}$, (d) $\left[\mathrm{C}_{8} \mathrm{mim}\right] \mathrm{Cl}$ and (e) $[\mathrm{Chol}] \mathrm{Cl}$ at: $94 \AA^{2}$ area per molecule. IL concentrations in the subphase correspond to the $\mathrm{EC}_{50}$ of $\left[\mathrm{C}_{6} \mathrm{mim}\right] \mathrm{Cl}\left(8.13 \times 10^{-4} \mathrm{mM}\right)$.

a higher thermodynamic cost for this coalescence, possibly as a result of the stronger electrostatic interactions established between DPPG and the choline cation.

The PM-IRRAS spectra in Fig. 14a show the methylene stretching vibrations for a DPPG monolayer at $30 \mathrm{mN} \mathrm{m}^{-1}$, with $\nu_{\text {as }}\left(\mathrm{CH}_{2}\right)=2851 \mathrm{~cm}^{-1}$ and $\nu_{\mathrm{s}}\left(\mathrm{CH}_{2}\right)=2918 \mathrm{~cm}^{-1}$, consistent with the literature. ${ }^{47,48}$ The symmetric $\mathrm{CH}_{2}$ stretching band shifted to larger wavenumbers upon incorporating ILs with increasing number of carbons in the alkyl chain, reaching $2923 \mathrm{~cm}^{-1}$ as shown in Fig. 14a. The shift is in the opposite direction to that observed for DPPC, which suggests that the ILs induce a disordering effect on the hydrocarbon chains of the DPPG monolayer. Indeed, Fig. 14b shows that the ratio $\nu_{\mathrm{a}}\left(\mathrm{CH}_{2}\right) /$ $\nu_{\mathrm{s}}\left(\mathrm{CH}_{2}\right)^{45,49,50}$ decreased from 1.6 to 0.2 as the number of carbon atoms in the alkyl chain increased. The opposite trend in chain ordering caused by ILs for DPPC and DPPG is probably related to the larger expansions in DPPG monolayers - compared to DPPC - and to the distinct effects on the head groups in the PM-IRRAS spectra seen below. It should be remarked, nevertheless, that a definitive explanation for the differences in chain order between DPPC and DPPG is still not available.

Also in contrast to the effects of ILs on DPPC, for DPPG the carbonyl ester group stretching band, $\nu(\mathrm{C}=\mathrm{O})$, shifted to larger wavenumbers from $1731 \mathrm{~cm}^{-1}$ for pure $\mathrm{DPPG}^{46,51,52}$ to $1740 \mathrm{~cm}^{-1}$ with incorporation of ILs with an increasing number of carbons in the alkyl chain. This is shown in Fig. 15a and b, and indicates that the $\mathrm{C}=\mathrm{O}$ environment becomes less hydrated in the presence of ILs.
In summary, the results with membrane models consisting of a neutral phospholipid (DPPC) have shown that different moieties of imidazolium-based ILs have distinct effects on the cell membrane and that long alkyl chains (with $n>6$ carbons) and more hydrophobic anions can cause major disruption of the monolayers. In principle, this can be translated into a mechanism of toxicity by disruption of the eukaryotic cell barrier, which also applies to the cholesterol monolayer. Electrostatic interactions do not seem to play a crucial role in the interaction mechanism of this type of ILs and the cell membrane, with hydrophobicity being the main factor. Preliminary molecular dynamics simulations for DPPC monolayers at the surface of aqueous solutions of $\left[\mathrm{C}_{n} \mathrm{mim}\right] \mathrm{Cl}$ are in good agreement with the experimental results confirming the penetration of longer alkyl chains into the phospholid monolayer and providing information on the location and orientation of the IL cations within the monolayer. It should be noted that the less hydrophobic imidazolium ILs and [Chol] Cl used in this study were in concentrations below their own $\mathrm{EC}_{50}$ whilst the more hydrophobic imidazolium ILs were used well above their own $\mathrm{EC}_{50}$; therefore the results obtained for the latter are exacerbated. The much larger effects induced by ILs on a negatively charged monolayer (DPPG) indicate that the cation has a severe effect on the cell membrane of bacteria via electrostatic interactions with the phospholipid headgroup, which is further aggravated by the hydrophobicity of both the alkyl chains and anion. 

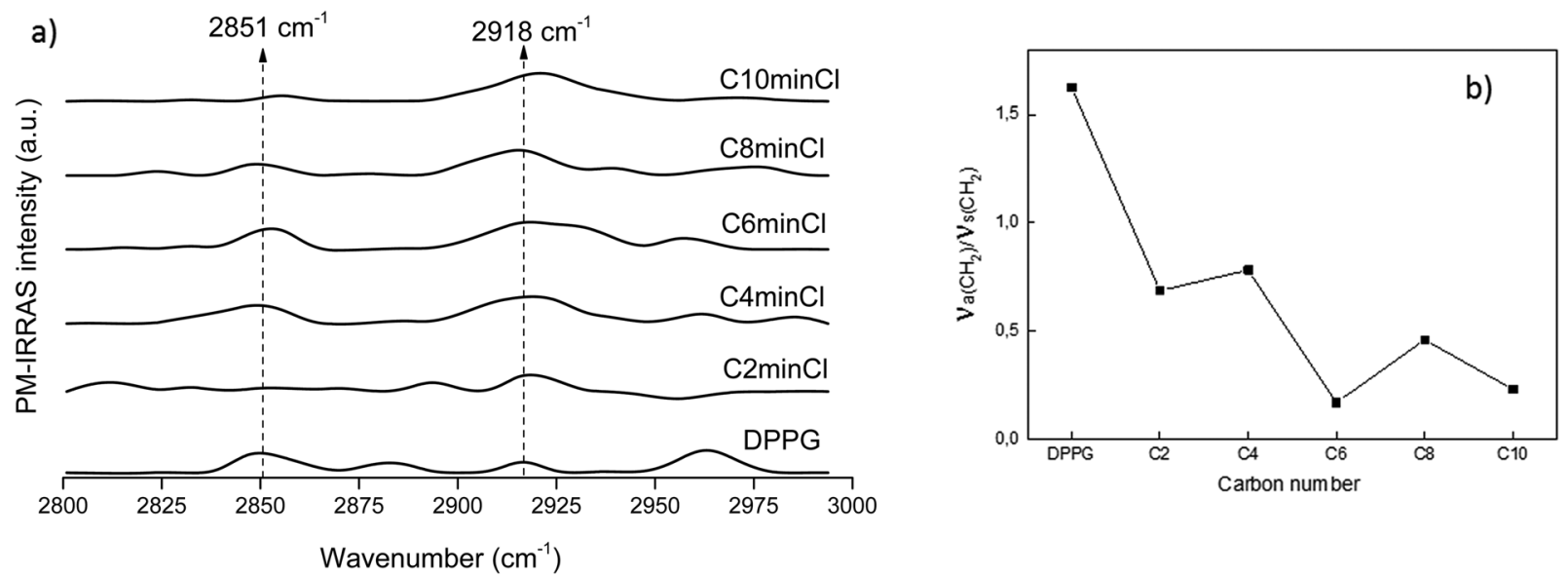

Fig. 14 PM-IRRAS spectra in the region of the methylene stretching bands $\left(2800-3000 \mathrm{~cm}^{-1}\right)$ for a pure DPPG monolayer (-) spread on a water subphase, and on aqueous solutions of ILs (a). Ratio of relative band intensities, $\nu_{a}\left(\mathrm{CH}_{2}\right) / \nu_{\mathrm{s}}\left(\mathrm{CH}_{2}\right)(\mathrm{b})$.
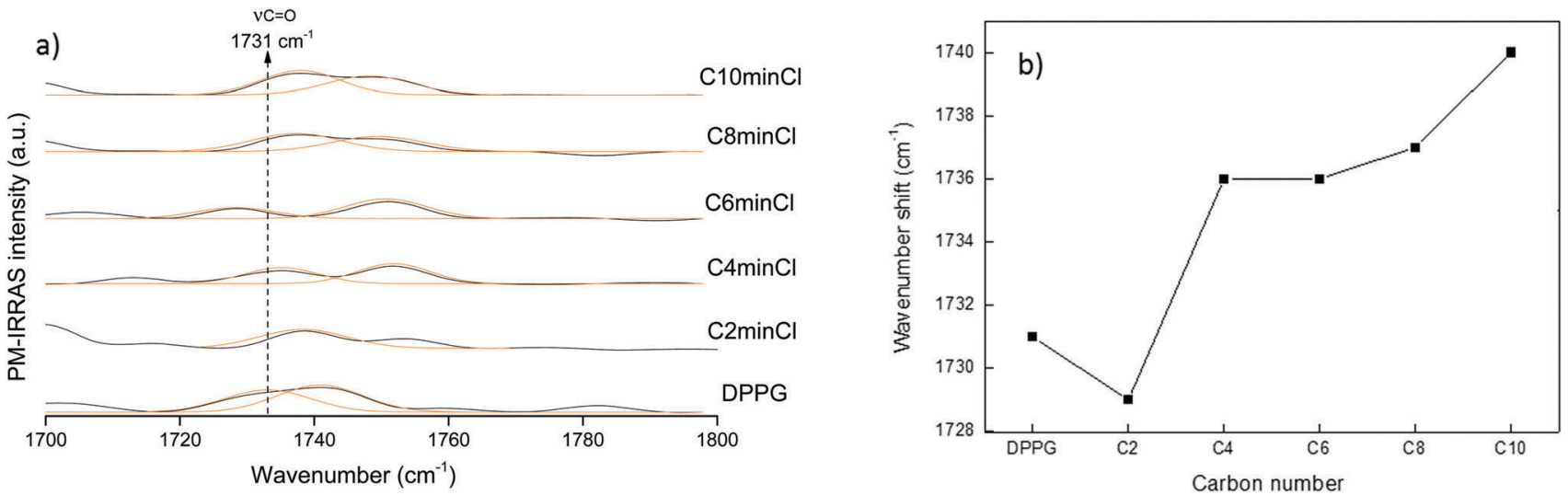

Fig. 15 (a) PM-IRRAS spectra in the region of the carbonyl stretching bands $\left(1800-1700 \mathrm{~cm}^{-1}\right)$ for a pure DPPG monolayer spread on a water subphase, and on aqueous solutions of ILs. Wavenumber shift of the vibration bands as a function of the number of carbons in the alkyl chain of ILs (b).

Despite the limitations inherent in the present study owing to the simplicity of the cell membrane models, the molecularlevel interactions between imidazolium ILs and the Langmuir monolayers seem to be in good agreement with the toxicity data reported for these compounds. Indeed, the results presented here support the proposed mechanism of disruption of the cell membranes by the more hydrophobic ILs, and thus could be of interest in the development of (Q)SAR models and to validate molecular simulations.

\section{Conclusions}

The present study has shown that imidazolium ILs used below the $\mathrm{EC}_{50}$ of $\left[\mathrm{C}_{6} \mathrm{mim}\right] \mathrm{Cl}$ do not have significant effect on the model cell membranes, especially when the alkyl chain has 6 or less carbon atoms. In contrast, imidazolium ILs with alkyl chains with $n>6$ and with more hydrophobic anions clearly lead to significant disruption of the cell membranes even though in the present study they were used in concentrations well above their own $\mathrm{EC}_{50}$. Furthermore, interactions between this type of cell membrane and ILs containing different cations, such as [Chol]Cl, seem to be negligible at the concentrations studied. In contrast, due to the electrostatic interactions established between the cations and the headgroups of negatively charged phospholipids, typical of bacterial cell membranes, the effect of ILs is rather dramatic, particularly as the hydrophobicity increases.

The results obtained show the potential of the use of Langmuir monolayers to obtain information regarding the interactions of different moieties of ILs with cell membrane components which may support the definition of descriptors in (Q)SAR models and help to validate molecular simulations.

\section{Conflicts of interest}

There are no conflicts to declare.

\section{Acknowledgements}

This work was developed within the scope of the project CICECOAveiro Institute of Materials, POCI-01-0145-FEDER-007679 
(FCT Ref. UID/CTM/50011/2013), financed by national funds through the FCT/MEC and when appropriate co-financed by FEDER under the PT2020 Partnership Agreement. Support was also obtained from CNPq and FAPESP (2013/14262-7) (Brazil). S. P. M. Ventura acknowledges FCT for the contract IF/00402/ 2015 under the Investigador FCT 2015. The authors are also grateful for the financial support of the FCT project PTDC/ATPEAM/5331/2014. LFGM acknowledges computational facilities from Instituto de Ciências da Terra (Évora University unit).

\section{References}

1 E. J. M. Filipe, P. Morgado and M. Teixeira, et al., Crystallinelike structures and multilayering in Langmuir films of ionic liquids at the air-water interface, Chem. Commun., 2016, 52(32), 5585-5588, DOI: 10.1039/C6CC01368F.

2 R. N. Das and K. Roy, Advances in QSPR/QSTR models of ionic liquids for the design of greener solvents of the future, Mol. Diversity, 2013, 17(1), 151-196, DOI: 10.1007/s11030-012-9413-y.

3 J. N. A. Canongia Lopes and A. A. H. Pádua, Nanostructural Organization in Ionic Liquids, J. Phys. Chem. B, 2006, 110(7), 3330-3335.

4 K. S. Egorova, E. G. Gordeev and V. P. Ananikov, Biological Activity of Ionic Liquids and Their Application in Pharmaceutics and Medicine, Chem. Rev., 2017, 117(10), 7132-7189, DOI: $10.1021 /$ acs.chemrev.6b00562.

5 A. Jordan and N. Gathergood, Biodegradation of ionic liquids - a critical review, Chem. Soc. Rev., 2015, 44(22), 8200-8237, DOI: 10.1039/C5CS00444F.

6 D. Muñoz-Torrero López-Ibarra, D. Haro Bautista and J. Vallès Xirau, Recent Advances in Pharmaceutical Sciences II, Transworld Research Network, 2012.

7 Organisation for Economic Co-operation and Development, 202. Daphnia Sp. Acute Immobilisation Test, OECD Publishing, 2004.

8 Organisation for Economic Co-operation and Development, Test No. 201: Freshwater Alga and Cyanobacteria, Growth Inhibition Test, OECD, 2011.

9 S. P. M. Ventura, M. Gurbisz and M. Ghavre, et al., Imidazolium and Pyridinium Ionic Liquids from Mandelic Acid Derivatives: Synthesis and Bacteria and Algae Toxicity Evaluation, ACS Sustainable Chem. Eng., 2013, 1(4), 393-402, DOI: 10.1021/ sc3001299.

10 S. P. M. Ventura, A. M. M. Gonçalves, F. Gonçalves and J. A. P. Coutinho, Assessing the toxicity on $\left[\mathrm{C}_{3} \mathrm{mim}\right]\left[\mathrm{Tf}_{2} \mathrm{~N}\right]$ to aquatic organisms of different trophic levels, Aquat. Toxicol., 2010, 96(4), 290-297, DOI: 10.1016/j.aquatox.2009.11.008.

11 M. V. S. Oliveira, B. T. Vidal and C. M. Melo, et al., (Eco)toxicity and biodegradability of protic ionic liquids, Chemosphere, 2016, 147, 460-466, DOI: 10.1016/J.CHEMO SPHERE.2015.11.016.

12 K. S. Egorova and V. P. Ananikov, Toxicity of Ionic Liquids: Eco(cyto)activity as Complicated, but Unavoidable Parameter for Task-Specific Optimization, ChemSusChem, 2014, 7(2), 336-360, DOI: 10.1002/cssc.201300459.
13 S. P. F. Costa, A. M. O. Azevedo, P. C. A. G. Pinto and M. L. M. F. S. Saraiva, Environmental Impact of Ionic Liquids: Recent Advances in (Eco)toxicology and (Bio)degradability, ChemSusChem, 2017, 10(11), 2321-2347, DOI: 10.1002/cssc.201700261.

14 J. I. Santos, A. M. M. Gonçalves and J. L. Pereira, et al., Environmental safety of cholinium-based ionic liquids: assessing structure-ecotoxicity relationships, Green Chem., 2015, 17(9), 4657-4668, DOI: 10.1039/C5GC01129A.

15 S. Ostadjoo, P. Berton, J. L. Shamshina and R. D. Rogers, Scaling-Up Ionic Liquid-Based Technologies: How Much Do We Care About Their Toxicity? Prima Facie Information on 1-Ethyl-3-Methylimidazolium Acetate, Toxicol. Sci, 2018, 161(2), 249-265, DOI: 10.1093/toxsci/kfx172.

16 J. D. Holbrey and K. R. Seddon, Ionic Liquids, Clean Technol. Environ. Policy, 1999, 1(4), 223-236, DOI: 10.1007/s100980050036.

17 European Union. Regulation (EC) no. 1907/2006 of the European parliament and of the Council concerning the Registration, Evaluation, Authorization and Restriction of Chemicals (REACH), Official J. Eur. Union, 2006;396:1-856.

18 C.-W. Cho, S. Stolte and Y.-S. Yun, Comprehensive approach for predicting toxicological effects of ionic liquids on several biological systems using unified descriptors, Sci. Rep., 2016, 6(1), 33403, DOI: 10.1038/srep33403.

19 R. N. Das and K. Roy, Advances in QSPR/QSTR models of ionic liquids for the design of greener solvents of the future, Mol. Diversity, 2013, 17(1), 151-196, DOI: 10.1007/s11030-012-9413-y.

20 R. N. Das, T. E. Sintra, J. A. P. Coutinho, S. P. M. Ventura, K. Roy and P. L. A. Popelier, Development of predictive QSAR models for Vibrio fischeri toxicity of ionic liquids and their true external and experimental validation tests, Toxicol. Res., 2016, 5(5), 1388-1399, DOI: 10.1039/C6TX00180G.

21 J. A. P. Coutinho, P. J. Carvalho and N. M. C. Oliveira, Predictive methods for the estimation of thermophysical properties of ionic liquids, $R S C A d v$. , 2012, 2(19), 7322, DOI: 10.1039/c2ra20141k.

22 B. Jing, N. Lan, J. Qiu and Y. Zhu, Interaction of Ionic Liquids with a Lipid Bilayer: A Biophysical Study of Ionic Liquid Cytotoxicity, J. Phys. Chem. B, 2016, 120(10), 2781-2789, DOI: 10.1021/acs.jpcb.6b00362.

23 V. K. Sharma and R. Mukhopadhyay, Deciphering interactions of ionic liquids with biomembrane, Biophys. Rev., 2018, 10(3), 721-734, DOI: 10.1007/s12551-018-0410-y.

24 T. M. Nobre, F. J. Pavinatto, L. Caseli, A. Barros-Timmons, P. Dynarowicz-Łątka and O. N. Oliveira, Interactions of bioactive molecules \& nanomaterials with Langmuir monolayers as cell membrane models, Thin Solid Films, 2015, 593, 158-188, DOI: 10.1016/J.TSF.2015.09.047.

25 A. A. Torrano, T. S. Pereira, O. N. Oliveira Jr and A. BarrosTimmons, Probing the interaction of oppositely charged gold nanoparticles with DPPG and DPPC Langmuir monolayers as cell membrane models, Colloids Surf., B, 2013, 108, 120-126.

26 G. Bhattacharya, R. P. Giri and H. Saxena, et al., X-ray Reflectivity Study of the Interaction of an Imidazolium-Based Ionic Liquid with a Soft Supported Lipid Membrane, Langmuir, 2017, 33(5), 1295-1304, DOI: 10.1021/acs.langmuir.6b03192. 
27 V. K. Sharma, S. K. Ghosh and P. Mandal, et al., Effects of ionic liquids on the nanoscopic dynamics and phase behaviour of a phosphatidylcholine membrane, Soft Matter, 2017, 13(47), 8969-8979, DOI: 10.1039/C7SM01799E.

28 D. Wang, D. H. de Jong and A. Rühling, et al., ImidazoliumBased Lipid Analogues and Their Interaction with Phosphatidylcholine Membranes, Langmuir, 2016, 32(48), 12579-12592, DOI: 10.1021/acs.langmuir.6b02496.

29 D. Van Der Spoel, E. Lindahl, B. Hess, G. Groenhof, A. E. Mark and H. J. C. Berendsen, GROMACS: fast, flexible, and free, J. Comput. Chem., 2005, 26(16), 1701-1718, DOI: 10.1002/jcc.20291.

30 S. Pronk, S. Páll and R. Schulz, et al., GROMACS 4.5: a highthroughput and highly parallel open source molecular simulation toolkit, Bioinformatics, 2013, 29(7), 845-854, DOI: 10.1093/bioinformatics/btt055.

31 W. L. Jorgensen, D. S. Maxwell and J. Tirado-Rives, Development and Testing of the OPLS All-Atom Force Field on Conformational Energetics and Properties of Organic Liquids, J. Am. Chem. Soc., 1996, 118(45), 11225-11236.

32 J. P. Ulmschneider and M. B. Ulmschneider, United Atom Lipid Parameters for Combination with the Optimized Potentials for Liquid Simulations All-Atom Force Field, J. Chem. Theory Comput., 2009, 5(7), 1803-1813, DOI: 10.1021/ct900086b.

33 J. Domański, P. J. Stansfeld, M. S. P. Sansom and O. Beckstein, Lipidbook: A Public Repository for Force-Field Parameters Used in Membrane Simulations, J. Membr. Biol., 2010, 236(3), 255-258, DOI: 10.1007/s00232-010-9296-8.

34 J. N. Canongia Lopes and A. A. H. Pádua, CL\&P: a generic and systematic force field for ionic liquids modeling, Theor. Chem. Acc., 2012, 131(3), 1129, DOI: 10.1007/s00214-012-1129-7.

35 J. L. F. Abascal and C. Vega, A general purpose model for the condensed phases of water: TIP4P/2005, J. Chem. Phys., 2005, 123(23), 234505, DOI: 10.1063/1.2121687.

36 S. P. M. Ventura, C. S. Marques, A. A. Rosatella, C. A. M. Afonso, F. Gonçalves and J. A. P. Coutinho, Toxicity assessment of various ionic liquid families towards Vibrio fischeri marine bacteria, Ecotoxicol. Environ. Saf., 2012, 76, 162-168, DOI: 10.1016/j.ecoenv.2011.10.006.

37 M. V. S. Oliveira, B. T. Vidal and C. M. Melo, et al., (Eco)toxicity and biodegradability of protic ionic liquids, Chemosphere, 2016, 147, 460-466, DOI: 10.1016/j.chemosphere.2015.11.016.

38 S. P. M. Ventura, F. A. e Silva, A. M. M. Gonçalves, J. L. Pereira, F. Gonçalves and J. A. P. Coutinho, Ecotoxicity analysis of cholinium-based ionic liquids to Vibrio fischeri marine bacteria, Ecotoxicol. Environ. Saf., 2014, 102, 48-54, DOI: 10.1016/ J.ECOENV.2014.01.003.

39 I. Martins, D. O. Hartmann and P. C. Alves, et al., Proteomic alterations induced by ionic liquids in Aspergillus nidulans and Neurospora crassa, J. Proteomics, 2013, 94, 262-278, DOI: $10.1016 /$ j.jprot.2013.09.015.

40 M. Petkovic, J. Ferguson and A. Bohn, et al., Exploring fungal activity in the presence of ionic liquids, Green Chem., 2009, 11(6), 889, DOI: 10.1039/b823225c.
41 C. W. McConlogue and T. K. Vanderlick, A Close Look at Domain Formation in DPPC Monolayers, Langmuir, 1997, 13(26), 7158-7164.

42 S. C. Barbosa, T. M. Nobre and D. Volpati, et al., The importance of cyclic structure for Labaditin on its antimicrobial activity against Staphylococcus aureus, Colloids Surf., B, 2016, 148, 453-459, DOI: 10.1016/j.colsurfb.2016.09.017.

43 V. P. N. Geraldo, F. J. Pavinatto, T. M. Nobre, L. Caseli and O. N. Oliveira, Langmuir films containing ibuprofen and phospholipids, Chem. Phys. Lett., 2013, 559, 99-106, DOI: 10.1016/J.CPLETT.2012.12.064.

44 G. B. Soriano, R. da Silva Oliveira, F. F. Camilo and L. Caseli, Interaction of non-aqueous dispersions of silver nanoparticles with cellular membrane models, J. Colloid Interface Sci., 2017, 496, 111-117, DOI: 10.1016/j.jcis.2017.02.017.

45 K. Czapla, B. Korchowiec and E. Rogalska, Differentiating Oxicam Nonsteroidal Anti-Inflammatory Drugs in Phosphoglyceride Monolayers, Langmuir, 2010, 26(5), 3485-3492, DOI: 10.1021/la903052t.

46 P. Garidel, A. Blume and W. Hübner, A Fourier transform infrared spectroscopic study of the interaction of alkaline earth cations with the negatively charged phospholipid 1,2dimyristoyl-sn-glycero-3-phosphoglycerol, Biochim. Biophys. Acta, Biomembr., 2000, 1466(1-2), 245-259, DOI: 10.1016/ S0005-2736(00)00166-8.

47 H. Bensikaddour, K. Snoussi and L. Lins, et al., Interactions of ciprofloxacin with DPPC and DPPG: fluorescence anisotropy, ATR-FTIR and ${ }^{31} \mathrm{P}$ NMR spectroscopies and conformational analysis, Biochim. Biophys. Acta, Biomembr., 2008, 1778(11), 2535-2543, DOI: 10.1016/j.bbamem.2008.08.015.

48 S. Malcharek, A. Hinz, L. Hilterhaus and H.-J. Galla, Multilayer Structures in Lipid Monolayer Films Containing Surfactant Protein C: Effects of Cholesterol and POPE, Biophys. J., 2005, 88(4), 2638-2649, DOI: 10.1529/biophysj.104.050823.

49 European Colloid and Interface Society. Conference (23rd: 2010): T. Antalya and S. Bucak, Trends in Colloid and Interface Science XXIII. Springer-Verlag, 2010. https://books.goo gle.pt/books/about/Trends_in_Colloid_and_Interfa ce_Science.html?id=l0M_kujIMSIC\&redir_esc=y. Accessed July 30, 2018.

50 N. K. Sarangi and A. Patnaik, Unraveling Tryptophan Modulated 2D DPPC Lattices: An Approach toward Stimuli Responsiveness of the Pulmonary Surfactant, J. Phys. Chem. B, 2011, 115(46), 13551-13562, DOI: 10.1021/jp207814g.

51 M. B. Decca, V. V. Galassi, M. Perduca, H. L. Monaco and G. G. Montich, Influence of the Lipid Phase State and Electrostatic Surface Potential on the Conformations of a Peripherally Bound Membrane Protein, J. Phys. Chem. B, 2010, 114(46), 15141-15150, DOI: 10.1021/jp104035z.

52 M. C. Sosa Morales, A. C. Juárez and R. M. S. Álvarez, Raman spectroscopy study of the interaction of 3,5,3'-triiodo-Lthyronine with phosphatidylglycerol lipid bilayers, J. Raman Spectrosc., 2015, 46(3), 302-308, DOI: 10.1002/jrs.4639. 